International Journal of Social Science and Economic Research

Volume:06, Issue:05 "May 2021"

\title{
COLOUR SYMBOLISM ACROSS CULTURES: A DICHOTOMY BETWEEN GERMAN AND INDIAN CONTEXTS
}

\author{
Dr. Shubhda Chaudhary, Soumi Dutt and Vanshika Gupta \\ Indraprastha College for Women - University Of Delhi
}

DOI: 10.46609/IJSSER.2021.v06i05.014 URL: https://doi.org/10.46609/IJSSER.2021.v06i05.014

\begin{abstract}
Hall (1994) interpreted symbols as something that stands for, represents or denotes a particular thing. Fadae (2011) further elucidated this concept and expressed symbolism, or the use of symbols, as an object, an attitude, a belief, or a value to represent an abstract idea; it takes something ordinary or basic and makes it more than what it is in reality. Colour is a critical cue for many vital behavioural tasks: material identification, object recognition and social-sexual signalling. Given the importance of the behavioural uses of colour, and the known perceptual and physiological properties of colour vision, it is likely that the preference for coloured objects drives preference for colours themselves. Therefore, it can be inferred that colour plays a significant role in various cognitive and physical functions.
\end{abstract}

Since there are 193 countries in the world, for this research paper, the sample size of the population has been concentrated to Germany and India. The sample size of the respondents has been restricted to the age group 16-55. This would help us to study better the contrasting colour preferences between the two countries.

The research question of the study is whether the symbolism of colour is interpreted in the German context as is interpreted in the Indian context. The formation of opinions regarding colour preferences will be the dependent variable and external factors such as geography, linguistic features and culture are the independent variables. Using eleven basic colour terms, as determined by Berlin and Kay (1969), subjects' perceptions of colour symbolism were explored through responses to an online survey shared with a global convenience sample. The findings have shown that culture affects the way we perceive colours symbolically. Data was found to both support and refute this hypothesis.

According to the Institute of Colour Research, "all human beings make an unconscious judgment about a person, environment, or item within ninety seconds of initial viewing and that between 62 percent and 90 percent of that assessment is based on colour alone" (cited in Morioka \& 


\section{International Journal of Social Science and Economic Research}

Volume:06, Issue:05 "May 2021"

Stone, 2006). While many people may not be explicitly aware of the symbolism they attach to a colour, decisions or perceptions are often influenced based on the presence of color.

The type of research is descriptive, and the source of data is primary and secondary, with asample size of 50 adults from Germany and India within the age group of 16-55. Questionnaires will be prepared for the collection of primary data. Online circulation of the questionnaire will be done. Moreover, a questionnaire collecting primary data will be prepared to understand how people belonging to different cultures associate colours to words in their mother tongue and third language. This research, therefore, aims to study the impact of culture on the way we perceive colours symbolically.

The research gap in this research paper is that the audience reaction for the questionnaire could not be gauged which is important to understand colour preferences. Moreover, the sample size was small due to the existence of geographical barriers.

Keywords: Symbols, symbolism, colour, cognitive, colour preferences, contrast

\section{INTRODUCTION}

Colour symbolism and colour terms can influence cognition, emotions, individual experiences, highlight cultural and religious differences as well as establish links between human activities, their state, their mood and psychological state (Saito, 2015). Surveys conducted to gauge colour preferences across numerous factors such as culture, geographical, gender etc. can be found among the very first psychological experiments ever conducted. Albeit, various examinations have been led on colour preferences, not many have focused on topographical areas, particularly from a multifaceted-cultural viewpoint.

Data from early surveys show the existence of various cultural differences between countries of geographical differences. For example, most countries in Asia like India and China view the colour white as a symbol of death and mourning (Gaparayan \& Astrayan,2011). Contrary to this, white as a symbol of colour holds significant importance for the population of Japan and is linked to the spiritual world as well as considered, a lucky colour. This can be traced back to Japanese literature with its mention of several characters accompanied by the colour white to emphasize the characters. Moreover, majority of the Japanese population consider the colours red and white to bring good luck and prosperity to their families; the colour scheme of which is comparable to the imagery of Japan's national flag (Saito, 2015). Experts have concluded that patriotism and feelings of nationalism and unity invoked by the flag's imagery can often influence the colour preference of different cultures. Similarly, red is the national colour of China and is often employed in several celebrations and festivities, the most notable of which is 


\section{International Journal of Social Science and Economic Research}

ISSN: $2455-8834$

Volume:06, Issue:05 "May 2021"

the celebration of Chinese New Year (Saito, 1996). The roots of such colour preferences can be traced back to folklore invoking the colour red as a part of its imagery to emphasise on the triumph of good over evil. Drawing inspiration from such folklore and colour preferences of the population, China's flag is coloured red. Unlike China and Japan, the northern and southern parts of India differ in their perspectives of the colour red. In North India, red is seen as an auspicious colour employed in the clothes of brides during a marriage ceremony and incorporated generously in the designing of Maa Durga during the auspicious event of Durga Puja. (Cultural Meanings of Colour and Colour Symbolism article, 2016). Conversely, the Southern part of India views the colour red as a symbol of violence and anger and associates it with that of negativity. (Winick, C., 1963). Contrasting the East, the West considers the colour white as a symbol of love and purity. Wedding ceremonies and brides often dress up in white to keep up with their culture and traditions. In the cultures of Muslim-dominated countries, Muslims wear white to their prayers every Friday as a symbol of purity and peace before God. Moreover, blue is symbolic of a protective colour in the countries of the Middle East which can be seen in the colouring of several mosques and monuments. The colour blue holds tremendous symbolic values in the artefacts and religious ideals of Buddhism as well. While countries of the East wear white as a symbol of mourning and death; mourning in the Western and Mediterranean countries are symbolized by black (Bradfield,2014).

Although there were stark differences in the use of colour and colour symbolism between countries of geographical differences, subsequent data analysis indicates that several countries prefer the blue colour in a phenomenon that Simon calls the Blue-Seven phenomenon (Simon, 1971). The "Blue-Seven Phenomenon" refers to Boutwell and Fennel (Boutwell and Fennel,1974) Simon's findings that all subjects indicated blue as their favourite colour and when asked to choose a number between zero and nine, majority of the subjects chose seven. This research pointed to the findings that blue was universally chosen as a favourite colour across several countries.

In several surveys, when associations with colours were asked to be made, it was inferred that subjects often associated colours with a feeling of pleasantness and unpleasantness. It was found that colours which made participants feel unpleasant were quicker to be pointed out than colours which made them feel pleasant. Cognitive studies back up this claim by explaining that the amygdala is intricately connected to the feelings of preference in terms of "pleasantness" and "unpleasantness", suggesting that these feeling play a significant role in the preference of colours (Shen, N.C., 1937). However, further studies reveal that general colour preferences cannot explain object-specific preferences. Studies on subjects showed that candidates took more time in deciding what their favourite colour was depending on the emotional, historical, cultural significance and past experiences of the said object. Objects can influence colour preference 


\section{International Journal of Social Science and Economic Research}

ISSN: $2455-8834$

Volume:06, Issue:05 "May 2021"

judgements, explaining the reason behind a relatively large amount of variability (Jonauskaite \& Mohr \& Antonietti \& Peter M. Spiers \& Betty Althaus \& Selin Anil \&Nele Dael, 2016).

Colourfulness or precisely, vividity, refers to an attribute of visual colour perception according to which colour shows more or less of its hue (Bradfield,2014). Related to the concept of vividity, accompanies a few more terms such as tones, saturation, tints and shadows. These terms are important to study to focus on the symbolic representation of colours across different cultures. The pure colour is called hue. Saturation (chroma) defines the brilliance and intensity of a colour. When a pigment hue is "toned," both white and black (grey) are added to the colour to reduce the colour's saturation. Black is added to the hue to create a shade. White is added to the hue to create a tint (William,1994). Value (lightness) describes overall intensity to how light or dark a colour is. It is the only dimension of colour that may exist by itself. An interesting distinction could be made between the ages of the subjects wherein it was noticed that children preferred louder and stronger colours and as the ages of the subjects gradually increased, they preferred lighter hues, muted variations of the pure colour. Another important distinction pointed to the fact that the colour preference of children aged three to seven years of age was generally similar and tend to diversify with age and the level of education (Adams, F.M., Osgood, C.E., 1973)

Language and culture play interchangeable roles in influencing the colour perception of subjects. As described by Douglas (1980), Language is one of the important constituents of culture. As human beings, we have a very developed visual sense, which is often reflected in the languages we speak (Uusküla \& Kalda, 2018). For example, idioms in the English language often combine the subtlety of text and the symbolic representation of colours to evoke feelings of emotions through imagery in a person's mind. Thus, all colours in general, have a set of emotions or symbolic meanings attached to them. The investigation concerning the translatability of colour terms leads to the assumption that the use of colour terms, found in proverbs and idioms, is based on a firm cultural background (Claire, 2017).

Colour terms, the associations, symbols and implied meanings of colour terms vary from nation to nation due to a variety of external factors as well such as environmental, climate, and religious beliefs. Colours tend to be either on the warm side (which means they have some red or yellow in them) or on the cool side (which means they have some blue in them) (Williams, 1994).Jaensch'sresearch indicates that those who live in climates with a lot of sunlight prefer warm bright colours; while those from climates with less sunlight prefer cooler, less saturated colours.(Gaparayan \& Astrayan,2011)

Thus, research was conducted keeping these parameters in mind, to test for the dichotomy between Indian and German contexts in terms of colour symbolism. 


\section{International Journal of Social Science and Economic Research}

ISSN: $2455-8834$

Volume:06, Issue:05 "May 2021"

\section{LITERATURE REVIEW}

"All human beings make an unconscious judgment about a person, environment, or item within ninety seconds of initial viewing and that between 62 per cent and 90 per cent of that assessment is based on colour alone" (cited Morioka \& Stone, 2006).

Surveys conducted on colour preferences date back to one of the very first psychological experiments, with several factors thought to be responsible for colour preferences. Quite a few studies have been conducted to investigate age and gender's impact on colour preferences however very few have been done taking geographical regions into account. Cross-cultural studies have been concentrated on European contexts and not many have compared the data with Asian countries and the influence of their culture on colour preference. There has been next to no research comparing Asian and German contexts and the influence of various factors such as age, gender, geographical area of residence, environmental factors, linguistic features. However, in the following relevant literature, different factors and their impact on colour preferences can be used to understand the topic better.

Berlin and Kay (1969) in their book Basic Color Terms: Their Universality and Evolution work proposed that the basic colour terms in a culture, such as black, brown, or red, are predictable by the number of colour terms the culture has. They interviewed native speakers of various languages to prove their hypotheses that different languages' colour lexicons are more similar than they would be if each language partitioned the colour space idiosyncratically and that within these limits there is further order in the way languages acquire new colour terms. They worked on understanding how certain languages don't have words to describe a certain colour shade. They worked on identifying basic colour terms identifiable in every culture. The original statements of Berlin and Kay's study have been significantly modified and loosened, but these broad ideas persist. For example, some languages fail to distinguish green and blue and some languages fail to distinguish red and yellow, but there are no languages that distinguish green and blue and fail to distinguish red and yellow.

A. CHOUNGOURIAN (1968) in his paper Colour Preferences and Cultural Variation states that there are explicit cultural differences in colour preferences. The research acknowledges that sex differences influence colour preferences though not in a very significant manner. However, there may be a need to set different norms for males and females in each culture to assess responses.

Erica L. Bradfield (2014) theses on The Diversity of Colour: An Analysis of Cross-Cultural Colour Symbolism states that unknowingly people's perceptions and decisions are influenced based on the presence of colours. The study states that the expression of various emotions in 


\section{International Journal of Social Science and Economic Research}

ISSN: $2455-8834$

Volume:06, Issue:05 "May 2021"

various cultures vary thereby affecting the way they are expressed in colours. Cultures that don't promote expression of emotions may have a more subdued or negative perception to the symbolism attributed to these emotions. On the other hand, positive perceptions have been noted in contrasting cultures. The research acknowledges the influence of globalization and social media and states that certain responses are uniform due to the ease of interaction between various cultures online. For example, responses to the constructs of anger, sadness, fear, death, and weddings may be influenced by the cultural trends seen online (i.e. I have heard that anger should be red, so I will answer red). The research calls these emotions statistically irrele vant in their study to understand colour preferences. It also states that cultures where emotions are freely expressed, perceptions of colour may change accordingly. Even though the data was statistically irrelevant to their study it adds value to our study and cross-cultural analysis since it establishes that certain factors affect colour preferences.

Simon and Primavera (1972) in their paper Investigation of the "blue seven phenomena" in elementary and junior high school children have reported $a$ "Blue Seven Phenomenon" among human subjects. The Blue Seven Phenomenon states that blue is a universally favourite colour. The phenomenon refers to Simon's findings that when subjects were asked to select their favourite colour and their favourite number, they selected blue and seven respectively. The studies conducted for the same haven't been researched using participants from India. Also, the sample of the study was majorly junior high school children. The study is still seen to be relevant as it gives insight in studying the blue seven phenomena.

Saito M. in his paper Comparative (Cross-cultural) Colour Preference and Its Structure demonstrated cross-cultural differences and similarities in colour preference among nine cultural groups. The groups were Americans, Germans, Danes, Australians, Papua New Guineans, South Africans, Japanese-Americans living in the USA, non-Japanese living in Japan, and Japanese. Four hundred subjects were asked to choose the colours they liked and disliked from among 65 coloured chips. The results of the study showed that vivid blue was the only colour that was commonly preferred highly by all groups. The study using other tools to interpret colour preference suggested that cultural variables are involved in influencing colour preference.

Yonglin Yang (2002), in his paper A Socio-Cognitive Study of University Students' Colour Codability in Chinese uses an experimental methodology. He deals with the sociolinguistic and psycholinguistic aspects of colour codability. The purpose of his paper is to observe the ability of university students' colour codability in Chinese and the influence of socio-cultural factors in the process. Colour words differ in the degree to which they provide a description or can be used for the naming of particular things, events, experiences, and states. Yang emphasizes the study of cognitive socio-cultural aspects of colour in Chinese. Even though the study only studies the 


\section{International Journal of Social Science and Economic Research}

ISSN: $2455-8834$

Volume:06, Issue:05 "May 2021"

colour codability among Chinese students it gives important insight into understanding how colour codability can be studied. It also highlights the importance of cognitive socio-cultural factors affecting colour codability.

There is a lot of literature dealing with colour theories, colour preferences, their meaning and interpretation. Most of this work is done in a limited geographic area. In all these references, very few have used a comparative approach to study colour preferences. However, these works have provided useful insight into understanding the appropriate method to study colour preferences.

\section{RESEARCH METHODS AND METHODOLOGY}

The research aimed to explore the dichotomy between German and Indian contexts through symbolic representation of colors. The independent variables were culture, language and geographical factors. Hall described Culture as a space of interpretative struggle. He further elucidated that media, society as well as language and geographical factors played a huge role in shaping up culture and how we perceive things. The dependent variable was colour symbolism. Some scholars explain colour symbolism as a branch of anthropology that refers to the use of different colours as certain symbols to evoke certain emotions in different cultures or the same culture in different time periods.

The process of sampling can be described as selecting a sample from the target population. In this context, the target population was the group of individuals aged from 16 to 55 years of age from whom a sample was drawn for the purpose of our research paper. A sample can be explained as the selected group of individuals who take part in the study. They are referred to as the participants. General is ability is the extent to which the results inferred from the sample group can be extended to the characteristics of the target population. Since we collected a nonrandom aka judgement sample from the target population, the general is ability of our results is comparatively on the lower scale. Since people who are willing and have the time are being tested on, the sample is also known as convenience sampling.

Experimental Design refers to how participants are allocated to different groups in an experiment. Repeated measures are a type of research methodology where the same participants are exposed to questions pertaining to the same research topic repeatedly to gauge a response from the participants. This kind of experimental design often reduces individual differences between the participants. In this context, we gave provided our participants with a questionnaire divided into five different sections. Each section focussed on finding results for the research topic and thus used reiterative approaches to draw results. Based on the results from which a conclusion was drawn, it was seen fit to match pairs of similar results in a form of methodology 


\section{International Journal of Social Science and Economic Research}

ISSN: $2455-8834$

Volume:06, Issue:05 "May 2021"

known as "Matched Pairs". Participants were divided into groups based on their results and a conclusion was drawn based on their characteristics.

Questionnaires were used to collect qualitative data for the research. Questionnaires are a great alternative to face-to-face interviews. It is a series of questions in written form to gather information from the respondents. Both open and closed questions were used to collect both qualitative and quantitative data. Closed questions are a series of questions, the answers to which have already been decided while allowing responses which fit only in pre-decided categories. Data that could be fit into categories ie. Nominal data was collected. Nominal data can be dichotomous such as yes or no answers or polytomous such as Strongly Disagree, Disagree, Don't have an opinion, Agree, Strongly Agree. Ordinal data ie, data that can be ranked can also be collected using closed questions. This often involves a rating scale to gauge the strength of attitudes and emotions. A trend was noticed in the pilot study conducted before the actual research. People tend to skip open questions that were placed strategically to collect qualitative data. Many tend to write one-worded answers or give answers that did not match with the onetailed hypothesis. It was concluded that boredom was one of the many reasons people did not reply to open questions and as a result, more closed questions were added as compared to open questions. As researchers, it had to be taken care that the research was carried out ethically and confidentially. Questionnaires are a great way of collecting data since confidentiality is maintained. Respondents are not restricted socially and can answer freely.

Pilot Studies are conducted before the actual test. Pilot studies are a way to gauge the validity of a questionnaire and used to reduce the occurrence of mistakes if any. Once the pilot test is conducted successfully, the researchers can proceed with the actual questionnaire. Our pilot study was performed on 10 respondents of whom 8 responded positively and so we decided to go ahead with the questionnaire to prove our research question.

Content Analysis is a research methodology used to indirectly observe the presence of certain words and meanings and deduce the themes and relationship between them as well as make inferences about the messages between them. Researchers quantify and analyse the relationship between words and meanings and deduce concepts that are being portrayed. To conduct content analysis in research, the media is broken down into specific groups and based on the participants' responses, an inference is made. In the context of our research paper, advertisements and the colour themes of different companies were considered. Respondents were asked to choose an alternative colour scheme that they felt fit the company's theme. Moreover, colour palettes containing four different colours were presented before the respondents and based on their preferences, an inference was drawn. Word Association and Emotional Responses to Colour were recorded as well. 
Meta-Analysis is the systematic review that involves identifying an aim and then searching for similar research papers and academic literature that have addressed the same. Using metaanalysis, several research papers and academic literature were perused, and conclusions were drawn from them. This helped to deduce a one-tailed hypothesis which helped in pursuing a particular direction for the context of the research paper.

Based on the results received from the questionnaires, it was decided to apply both quantitative and qualitative methods of research to the data collected. The qualitative analysis helped us to study how human beings perceive certain colours and in turn, how they react in certain social contexts. Various documents and artefacts were gone through, personal experiences of people played a huge role in drawing conclusions. This helped to draw a conclusion based on social phenomenon. Quantitative research was employed to discover the facts surrounding the social phenomenon. Various statistical analyses were employed to make sense of the data.

Taking into consideration the results of such surveys, we decided to create a three-layered diagram consisting of culture and language as the innermost layer or the nucleus followed by the environmental and geographical factors affecting colour perception as the second layer and extra-linguistic factors such as the time-period, globalisation, expression of colours and personal preferences as the outermost layer. There search question pertains to whether geographical differences affect colour preferences. The formation of opinion regarding colour preferences will be the dependent variable and external factors such as geography, linguistic features and culture are the independent variables.

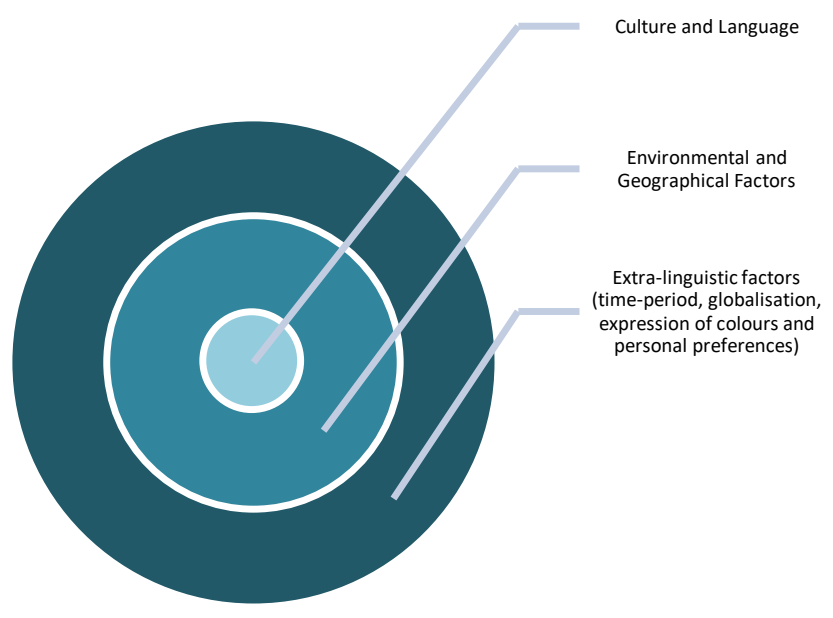

Three-layered diagram explaining the variables in the study 


\section{DATA COLLECTION METHODS}

Primary data collection method was used to gather 50 responses from respondents in the agegroup16-55 years of age, residing in India and Germany through online surveys for the purpose of this research paper. A pilot study was undertaken a planned sample size of 20 people of age group16-55.

SECTION - 1: The first section comprised of colour palettes consisting four different colours to infer colour preferences of respondents.

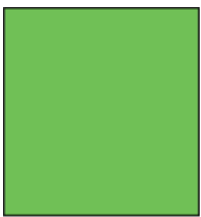

1

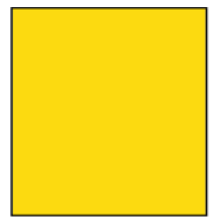

2

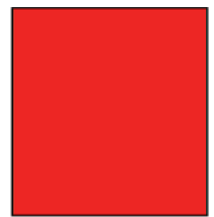

3

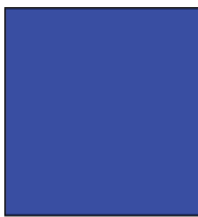

4

Favourite Colour : 1st Preference

54 responses
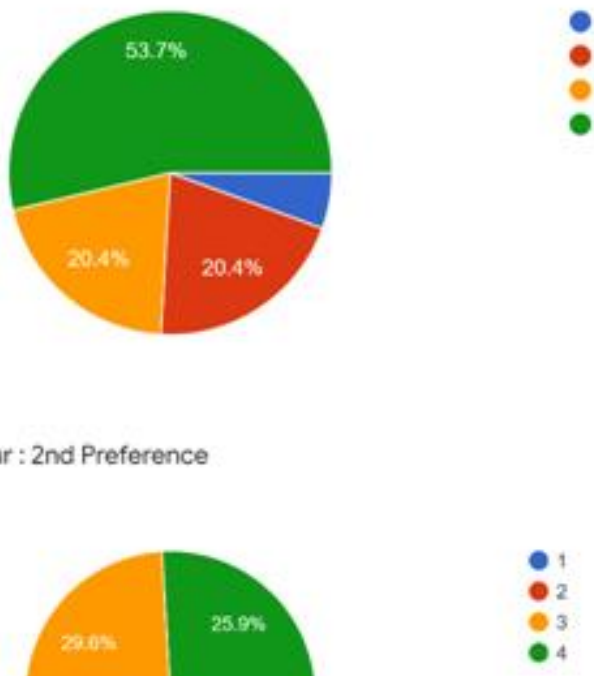

Favourite Colour : 2nd Preference

54 responses

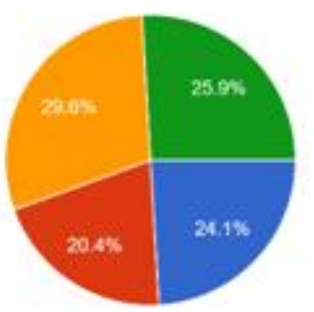


International Journal of Social Science and Economic Research

ISSN: $2455-8834$

Volume:06, Issue:05 "May 2021"
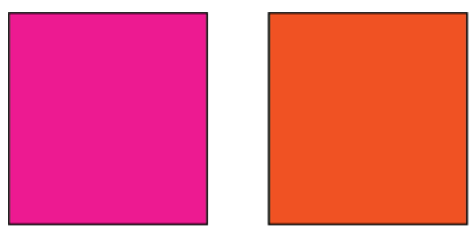

1

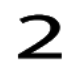

3

Favourite Colour - 1st Preference 54 responses

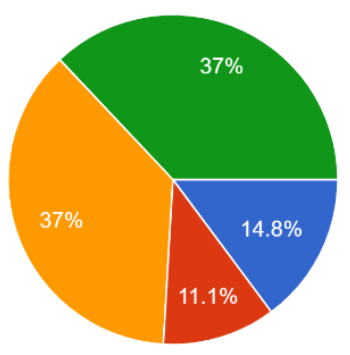

Favourite Colour : 2nd Preference 54 responses

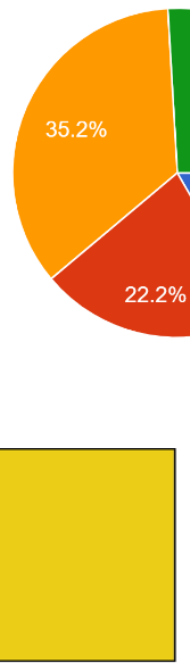

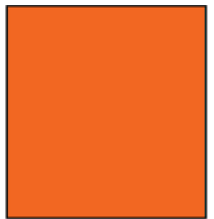

3
1

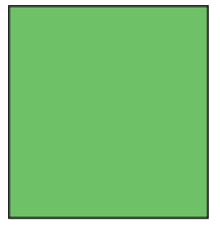

2
$25.9 \%$

$16.7 \%$

\section{$2.2 \%$}
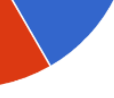
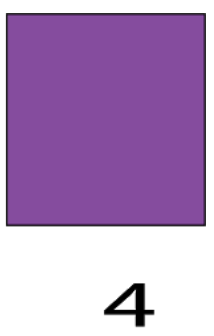

4

1

2

3

4 
Favourite Colour : 1st Preference 54 responses
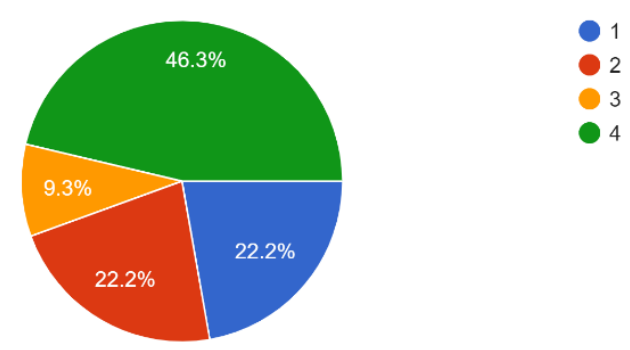

Favourite Colour : 2nd Preference 54 responses
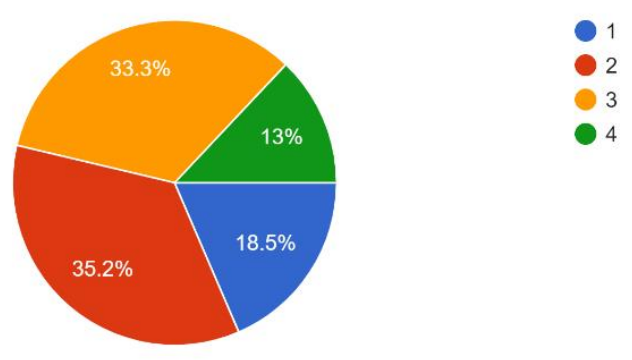

Which of the three colour palettes was visually, the most pleasing? 54 responses
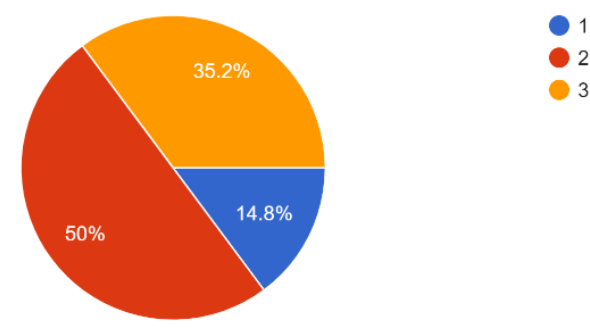

3

SECTION - 2 :The second section comprised of colour palettes consisting four different saturation level of the same colour. The preference for lighter or darker hues of the same colour was meant to be tested. 
International Journal of Social Science and Economic Research

ISSN: $2455-8834$

Volume:06, Issue:05 "May 2021"

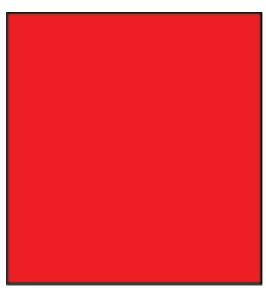

1

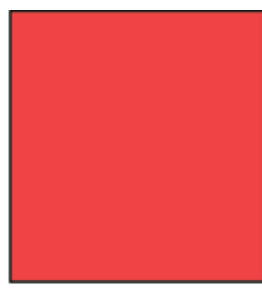

2

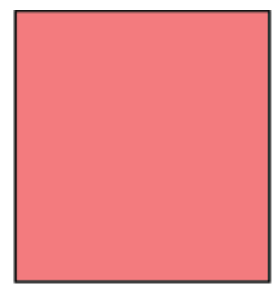

3

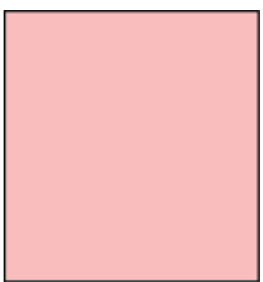

4

Choose Your First Preference 54 responses

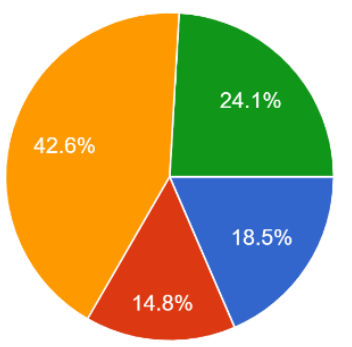

1

2

3

4

Choose Your Second Preference

54 responses

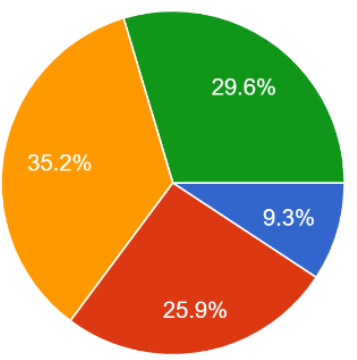

(1)

3

4
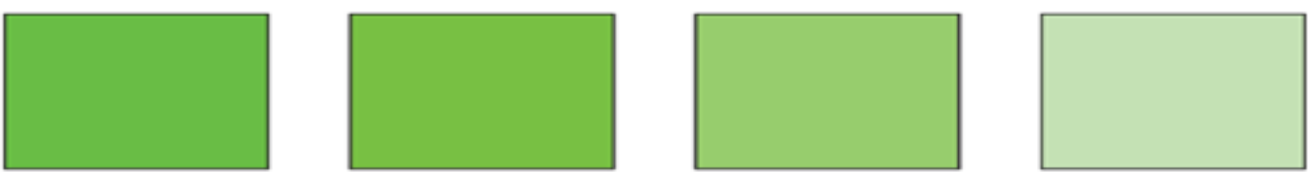

1

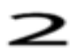

3

4 
Choose Your First Preference

54 responses

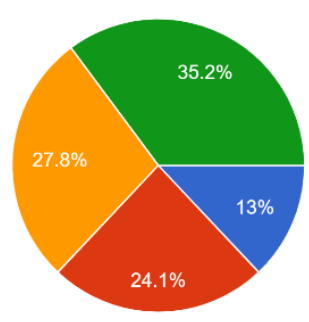

1

3

4

Choose Your Second Preference

54 responses

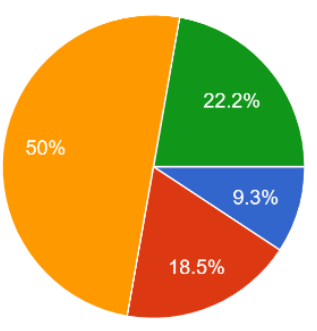

1

2

3

4
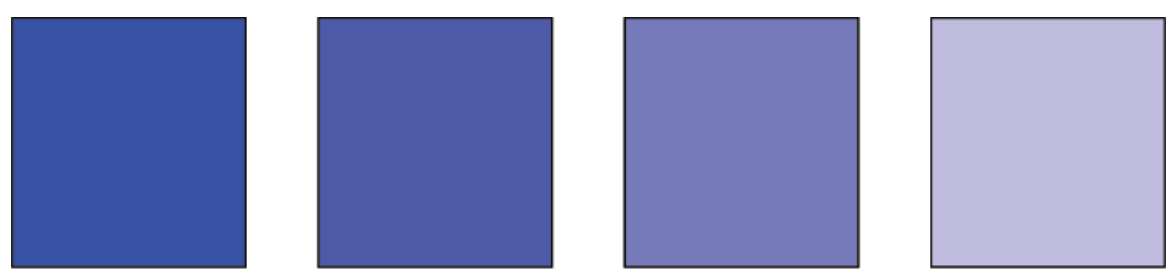

1

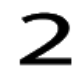

3

4

Choose Your First Preference 54 responses

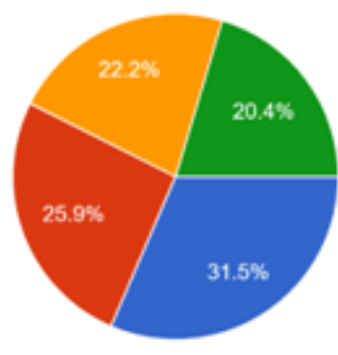


International Journal of Social Science and Economic Research

ISSN: $2455-8834$

Volume:06, Issue:05 "May 2021"

Choose Your Second Preference

54 responses

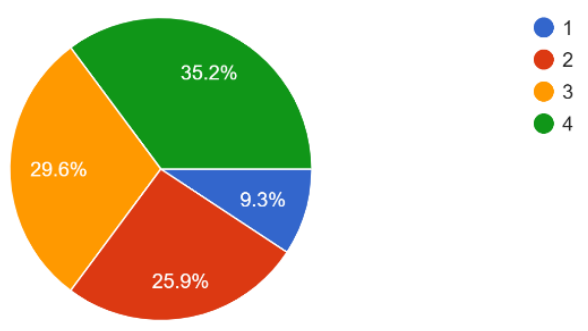

SECTION - 3: The third section tested respondents on the colours they symbolically associated to different emotions.

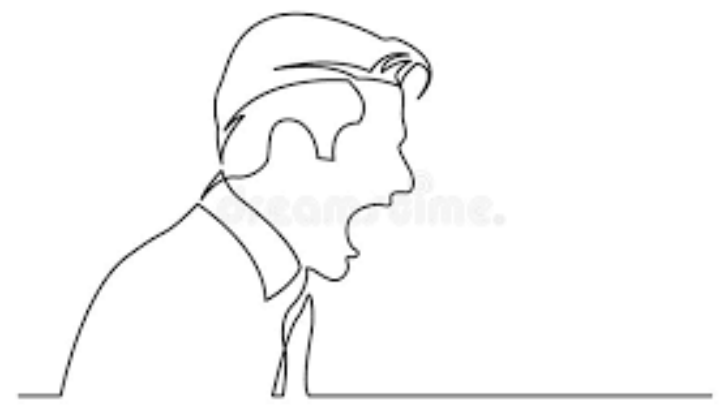

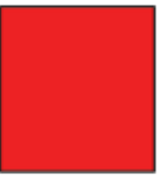

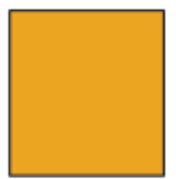

1

2
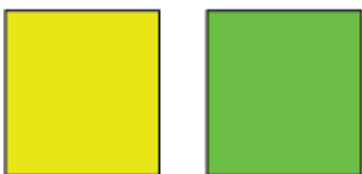

3

Which Colour Do You Associate This Picture With? 54 responses

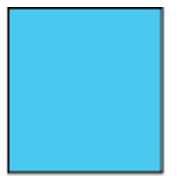

5

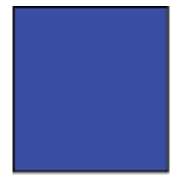

6

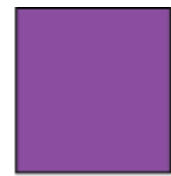

7

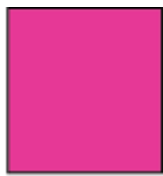

8

Which Colour Do You Associate This Picture With? 54 responses
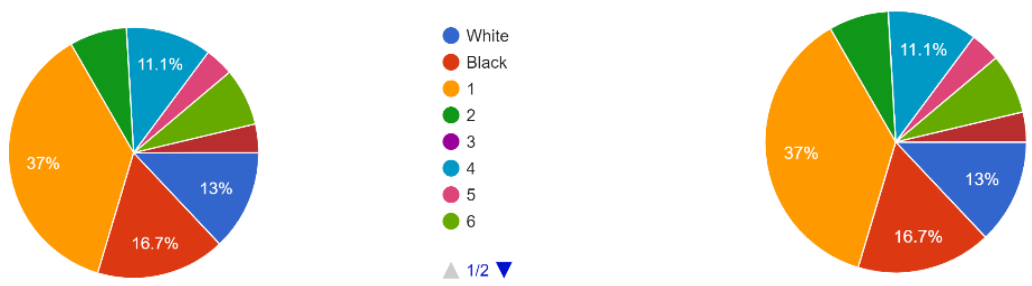

7

8

A $2 / 2 \nabla$ 

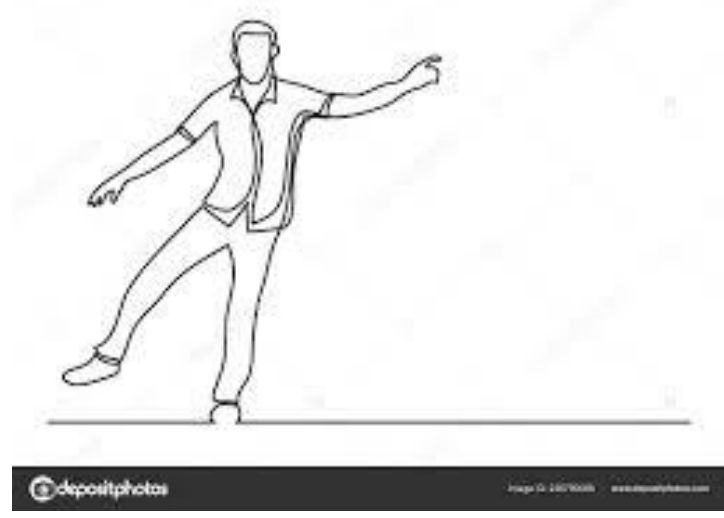

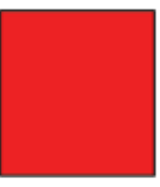

1

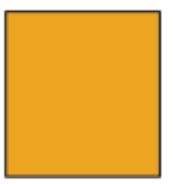

2

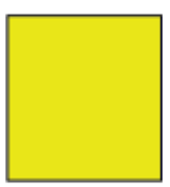

3

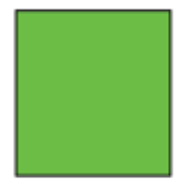

4

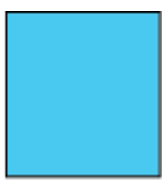

5

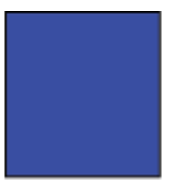

6

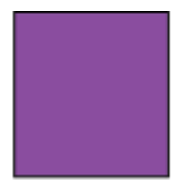

7

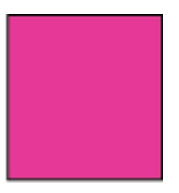

8
Which Colour Do You Associate This Picture With? 54 responses
Which Colour Do You Associate This Picture With? 54 responses

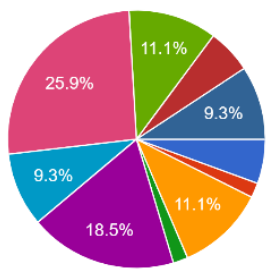

-7
8

$\Delta 2 / 2 \nabla$
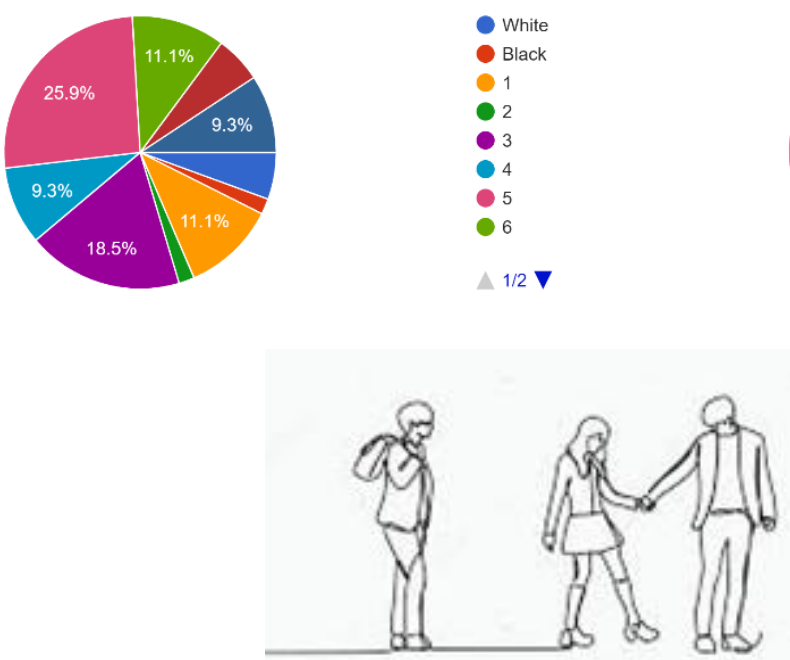
International Journal of Social Science and Economic Research

ISSN: $2455-8834$

Volume:06, Issue:05 "May 2021"

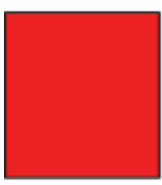

1

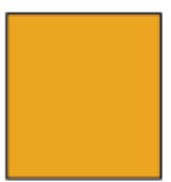

2

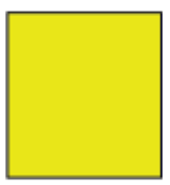

3

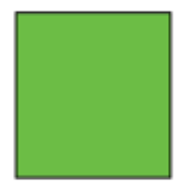

4

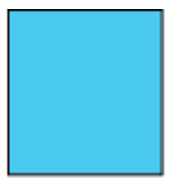

5

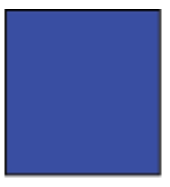

6

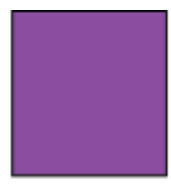

7

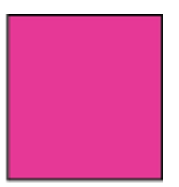

8

Which Colour Do You Associate This Picture With?

Which Colour Do You Associate This Picture With? 54 responses
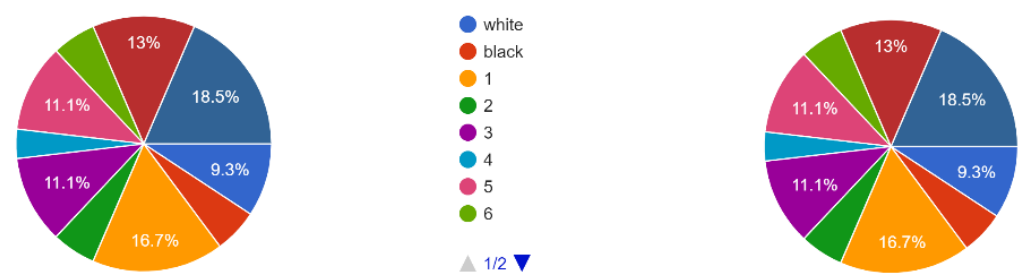

7
8

$\boldsymbol{\Delta} 2 / 2 \nabla$

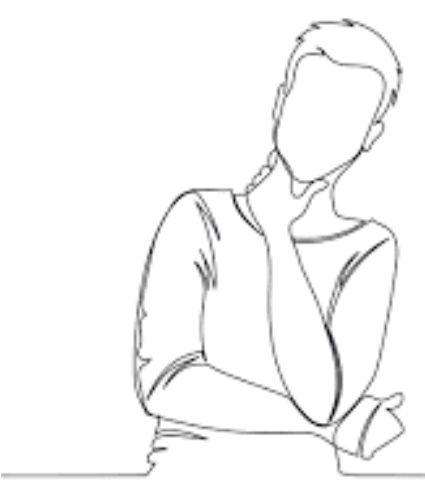

'Weckistock'

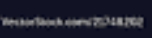

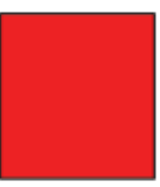

1

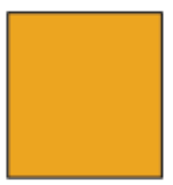

2

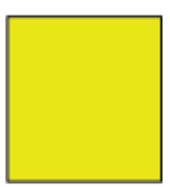

3

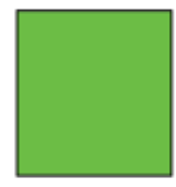

4

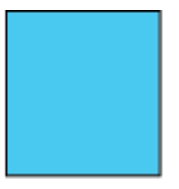

5

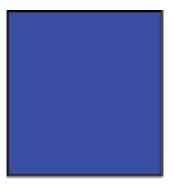

6

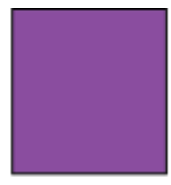

7

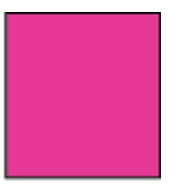

8 
International Journal of Social Science and Economic Research

ISSN: $2455-8834$

Volume:06, Issue:05 "May 2021"

Which Colour Do You Associate This Picture With? 54 responses

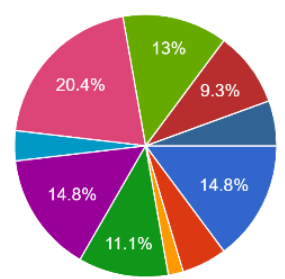

Which Colour Do You Associate This Picture With? 54 responses

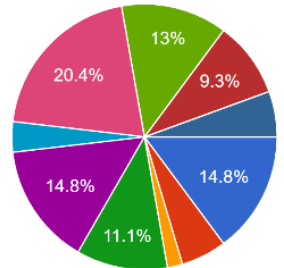

7

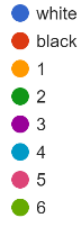

$\Delta 1 / 2 \nabla$
8

$\mathbf{\Delta} 2 / 2$

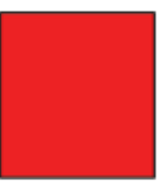

1

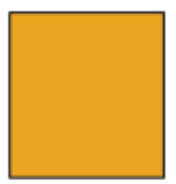

2

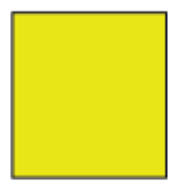

3

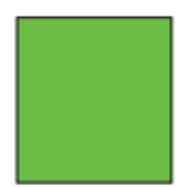

4

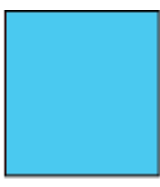

5

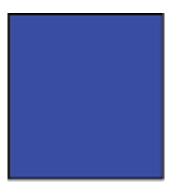

6

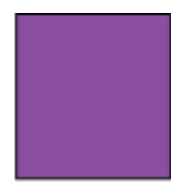

7

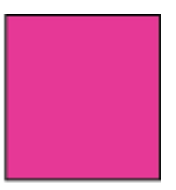

8

Which Colour Do You Associate This Picture With? 54 responses
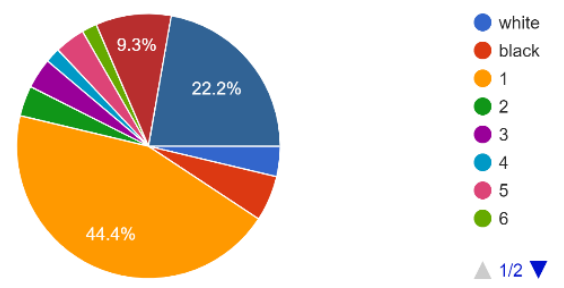

Which Colour Do You Associate This Picture With? 54 responses

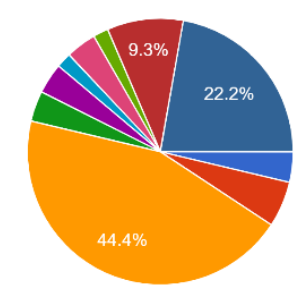

7
0

$\boldsymbol{\Delta} 2 / 2 \nabla$ 
International Journal of Social Science and Economic Research

ISSN: $2455-8834$

Volume:06, Issue:05 "May 2021"

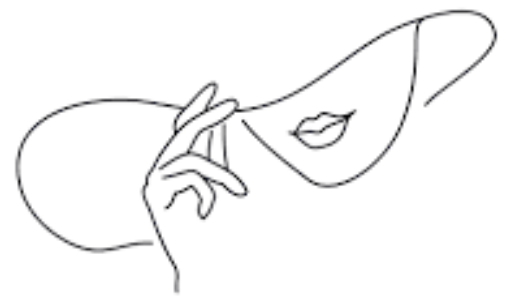

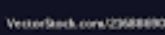

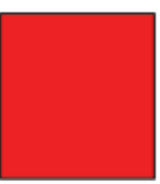

1

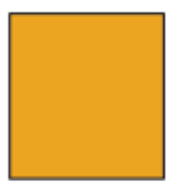

2

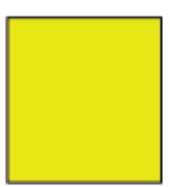

3

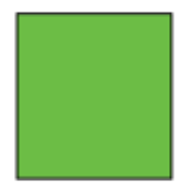

4

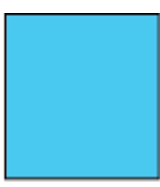

5

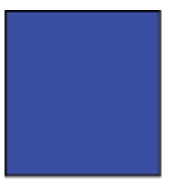

6

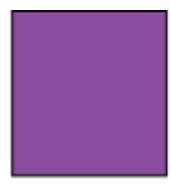

7

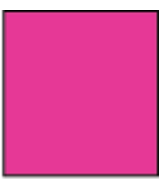

8
Which Colour Do You Associate This Picture With? 54 responses
Which Colour Do You Associate This Picture With? 54 responses
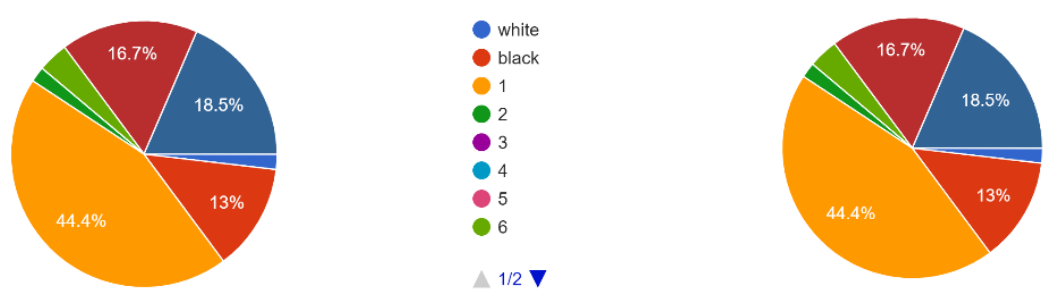

7
8

$\Delta 2 / 2$

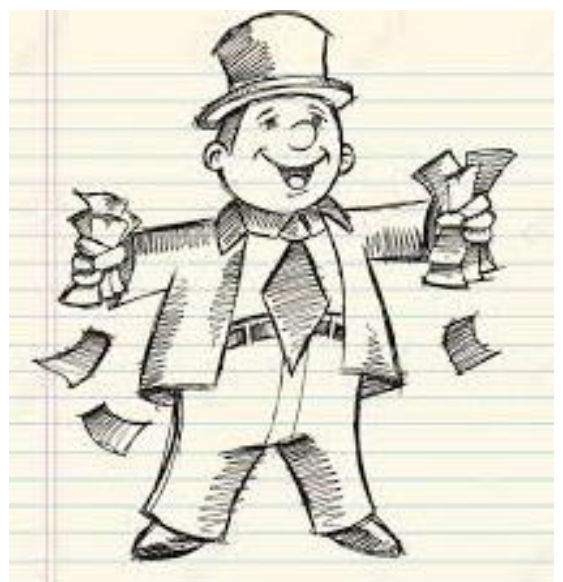


International Journal of Social Science and Economic Research

ISSN: $2455-8834$

Volume:06, Issue:05 "May 2021"

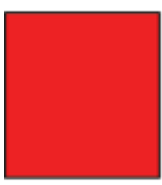

1

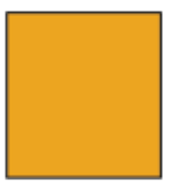

2

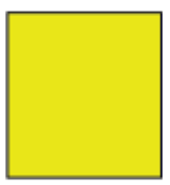

3

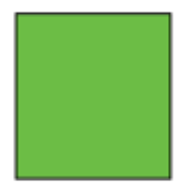

4

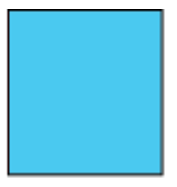

5

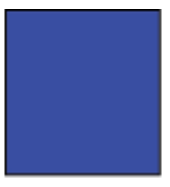

6

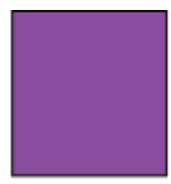

7

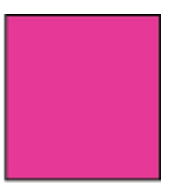

8
Which Colour Do You Associate This Picture With? 54 responses

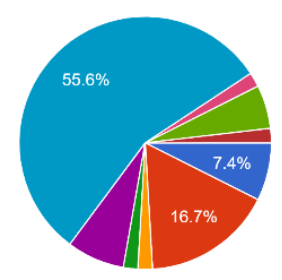

Which Colour Do You Associate This Picture With? 54 responses

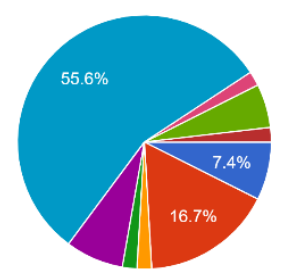

-1
-

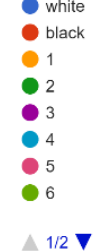

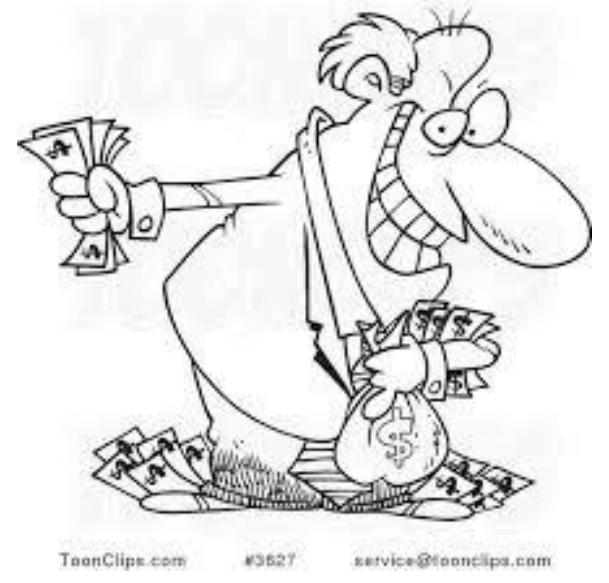

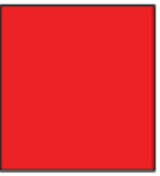

1

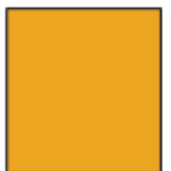

2

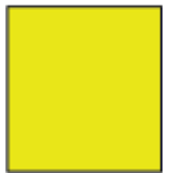

3

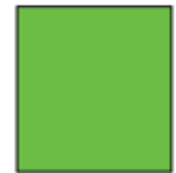

4

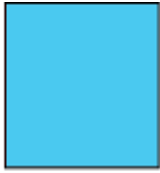

5

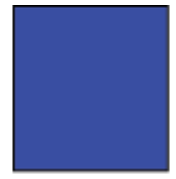

6

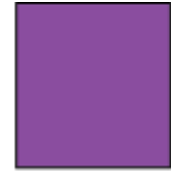

7

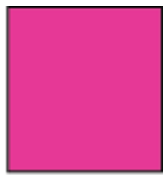

8 
International Journal of Social Science and Economic Research

ISSN: $2455-8834$

Volume:06, Issue:05 "May 2021"

Which Colour Do You Associate This Picture With? 54 responses

Which Colour Do You Associate This Picture With? 54 responses
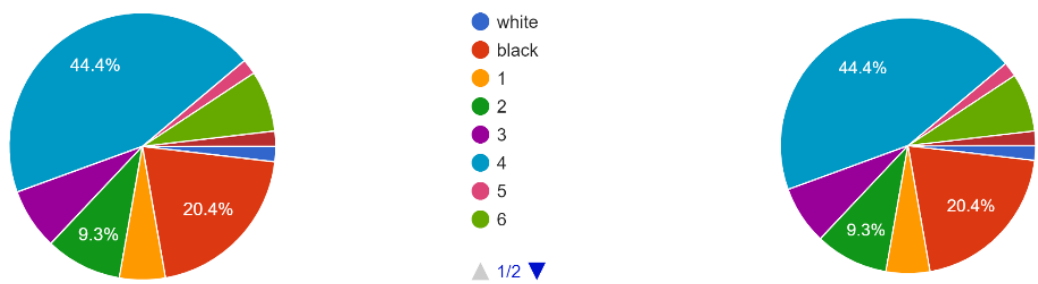

7
8

$\Delta 2 / 2 \nabla$

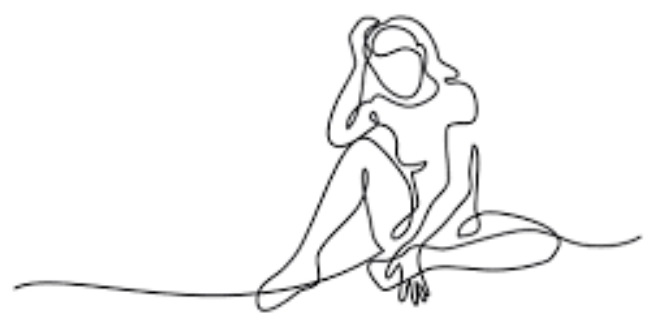

VectorStock

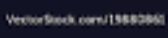

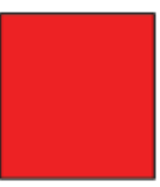

1

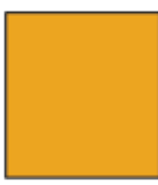

2

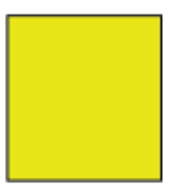

3

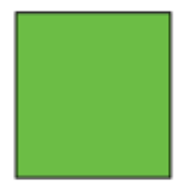

4

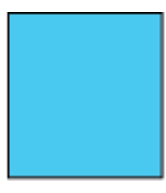

5

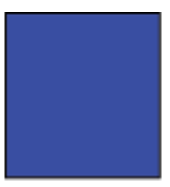

6

Which Colour Do You Associate This Picture With? 54 responses

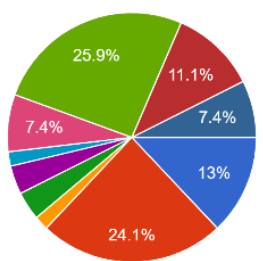

7
0

$\Delta 2 / 2 \nabla$ 
International Journal of Social Science and Economic Research

ISSN: $2455-8834$

Volume:06, Issue:05 "May 2021"

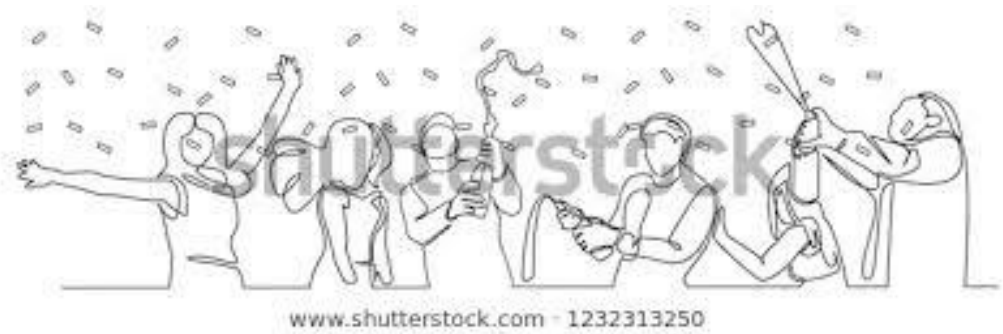

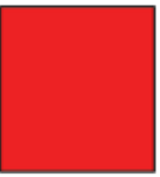

1

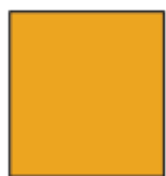

Which Colour Do You Associate This Picture With? 54 responses
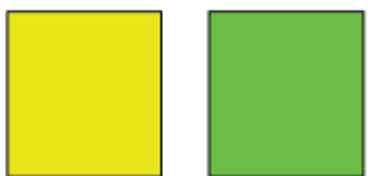

3

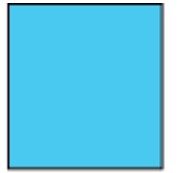

5

4

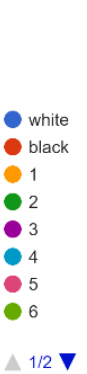

Which Colour Do You Associate This Picture With? 54 responses
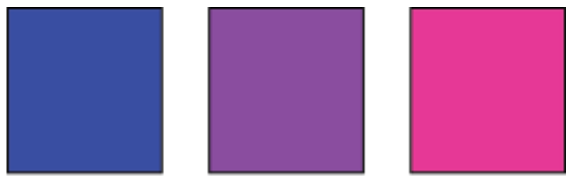

8
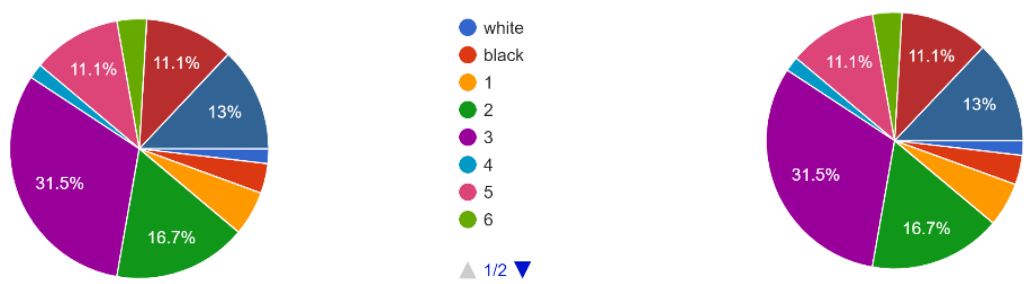

7
8

$\boldsymbol{\Delta} 2 / 2 \nabla$

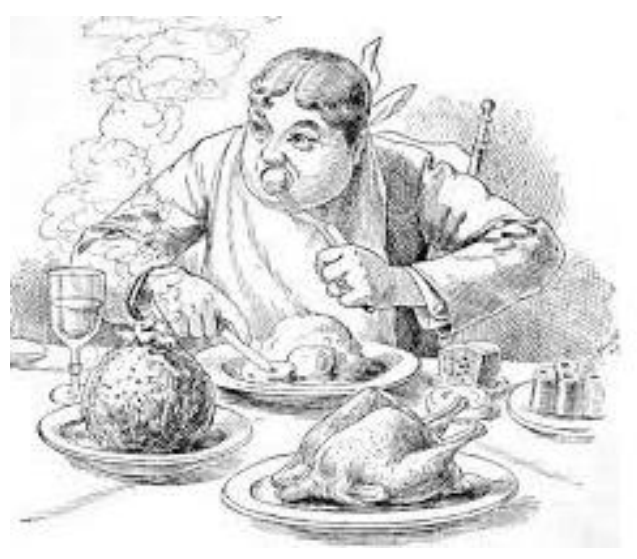


International Journal of Social Science and Economic Research

ISSN: $2455-8834$

Volume:06, Issue:05 "May 2021"

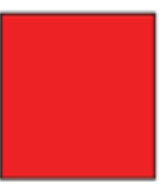

1

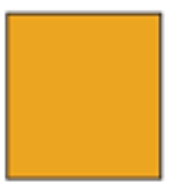

2

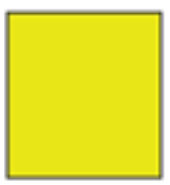

3

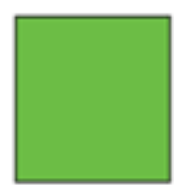

4

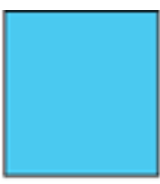

5

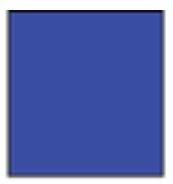

6

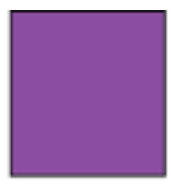

7

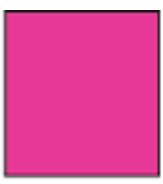

8

Which Colour Do You Associate This Picture With? 54 responses
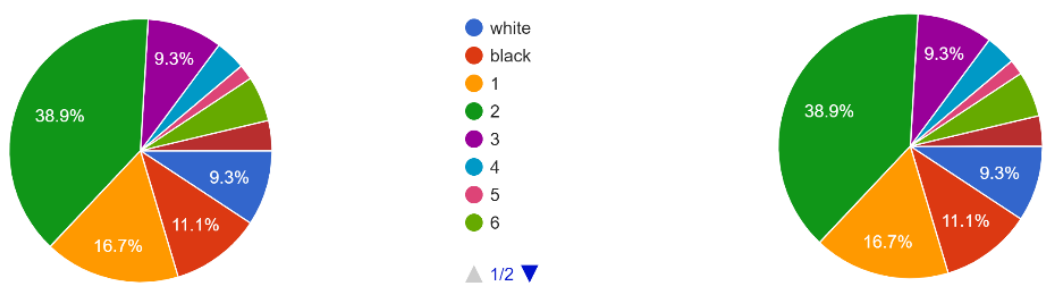

7

Which Colour Do You Associate This Picture With? 54 responses

$\Delta 2 / 2 \nabla$

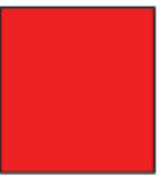

1

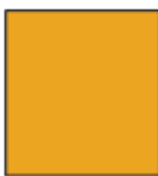

2
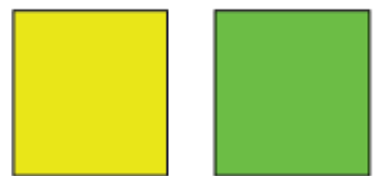

3

Which Colour Do You Associate This Picture With? 54 responses

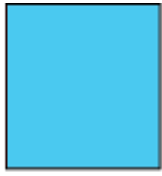

5

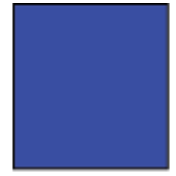

6

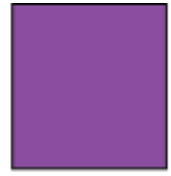

7

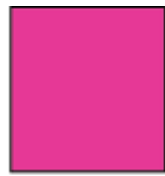

8
Which Colour Do You Associate This Picture With? 54 responses
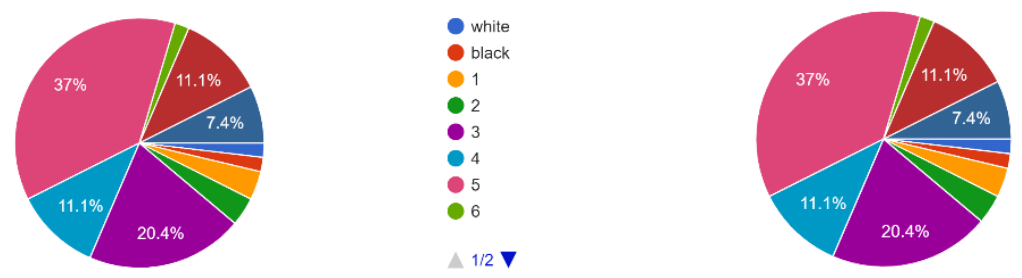

7
8

$1 / 2 \boldsymbol{\nabla}$

$\Delta 2 / 2 \nabla$ 

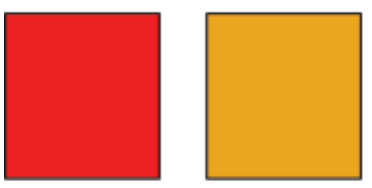

1

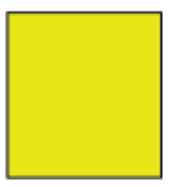

3

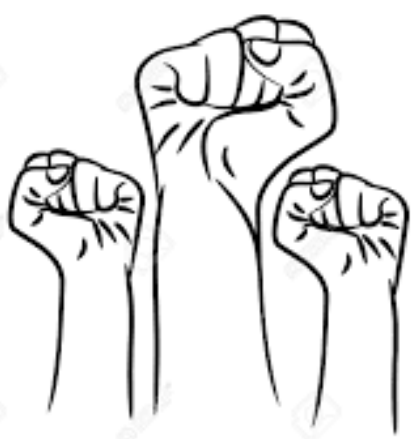

Which Colour Do You Associate This Picture With? 54 responses

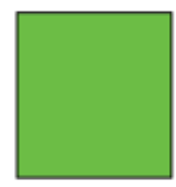

4

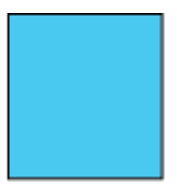

5

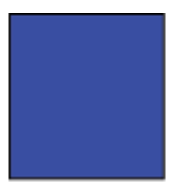

6

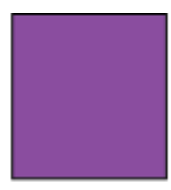

7

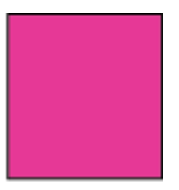

8

Which Colour Do You Associate This Picture With? 54 responses
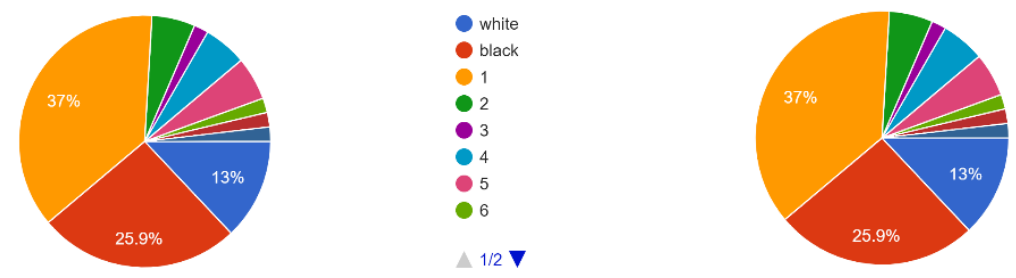

7

$\Delta 2 / 2 \nabla$

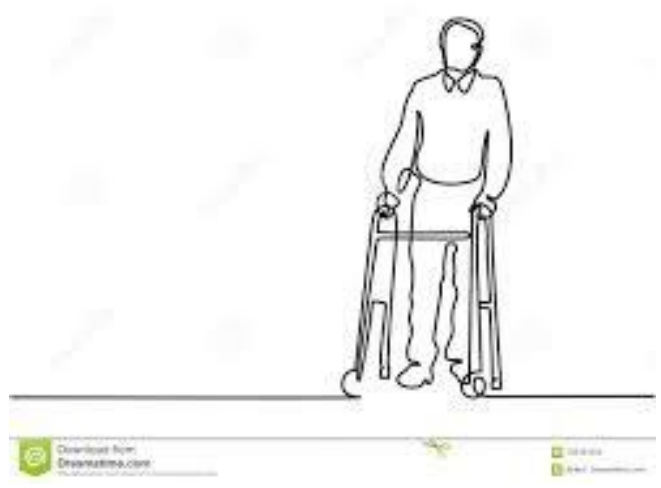


International Journal of Social Science and Economic Research

ISSN: $2455-8834$

Volume:06, Issue:05 "May 2021"

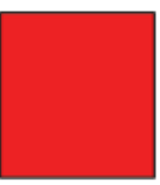

1

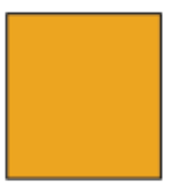

2

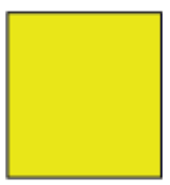

3

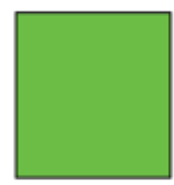

4

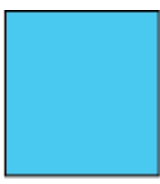

5

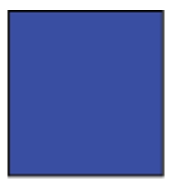

6

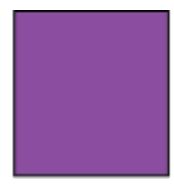

7

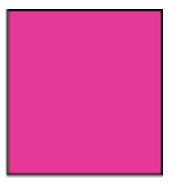

8
Which Colour Do You Associate This Picture With? 54 responses
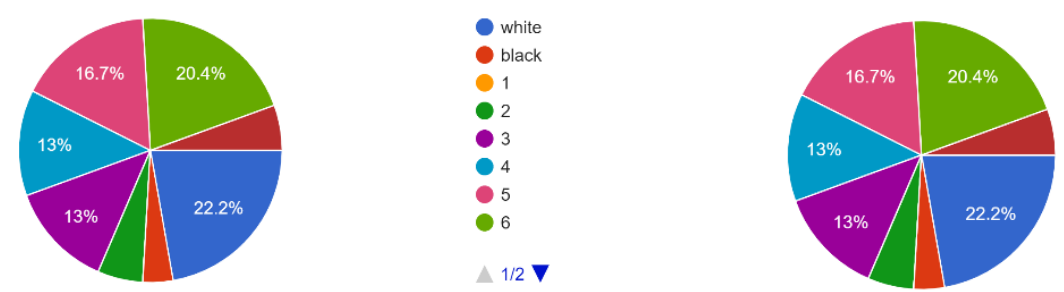

7

$\boldsymbol{\Delta} 2 / 2 \nabla$

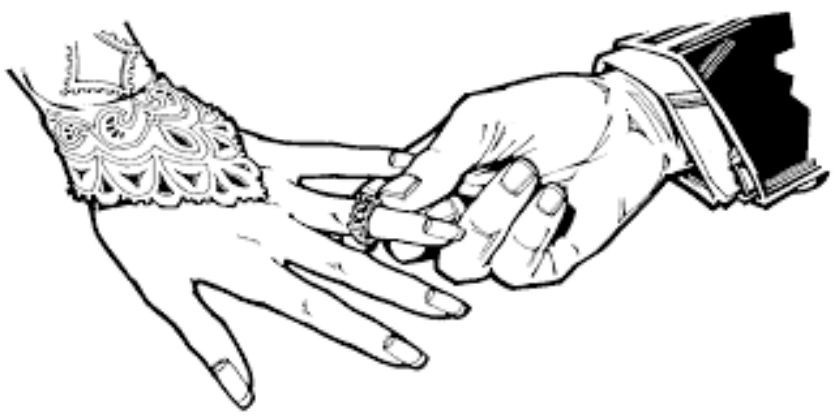

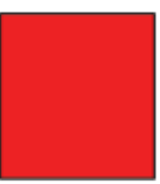

1

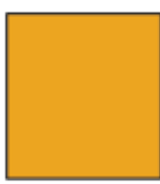

2

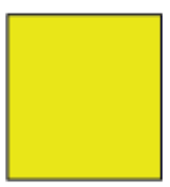

3

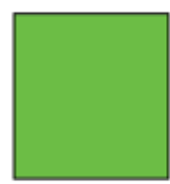

4

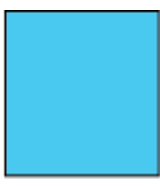

5

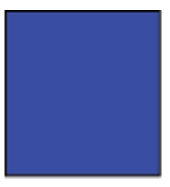

6

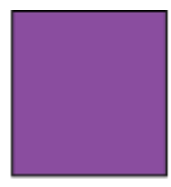

7

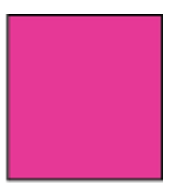

8

Which Colour Do You Associate This Picture With?

Which Colour Do You Associate This Picture With? 54 responses
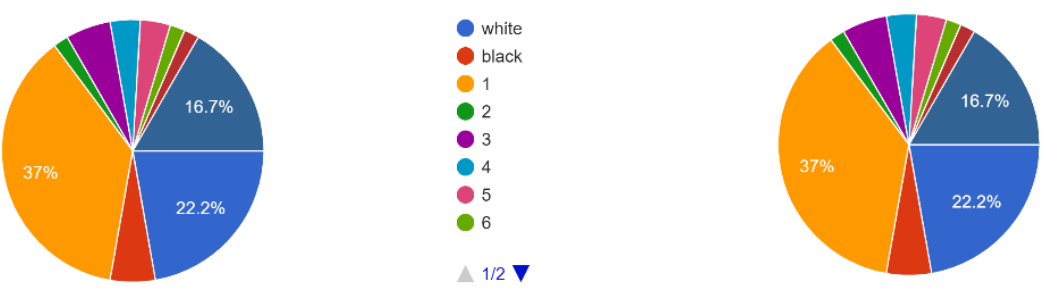

7

$\Delta 2 / 2 \nabla$ 


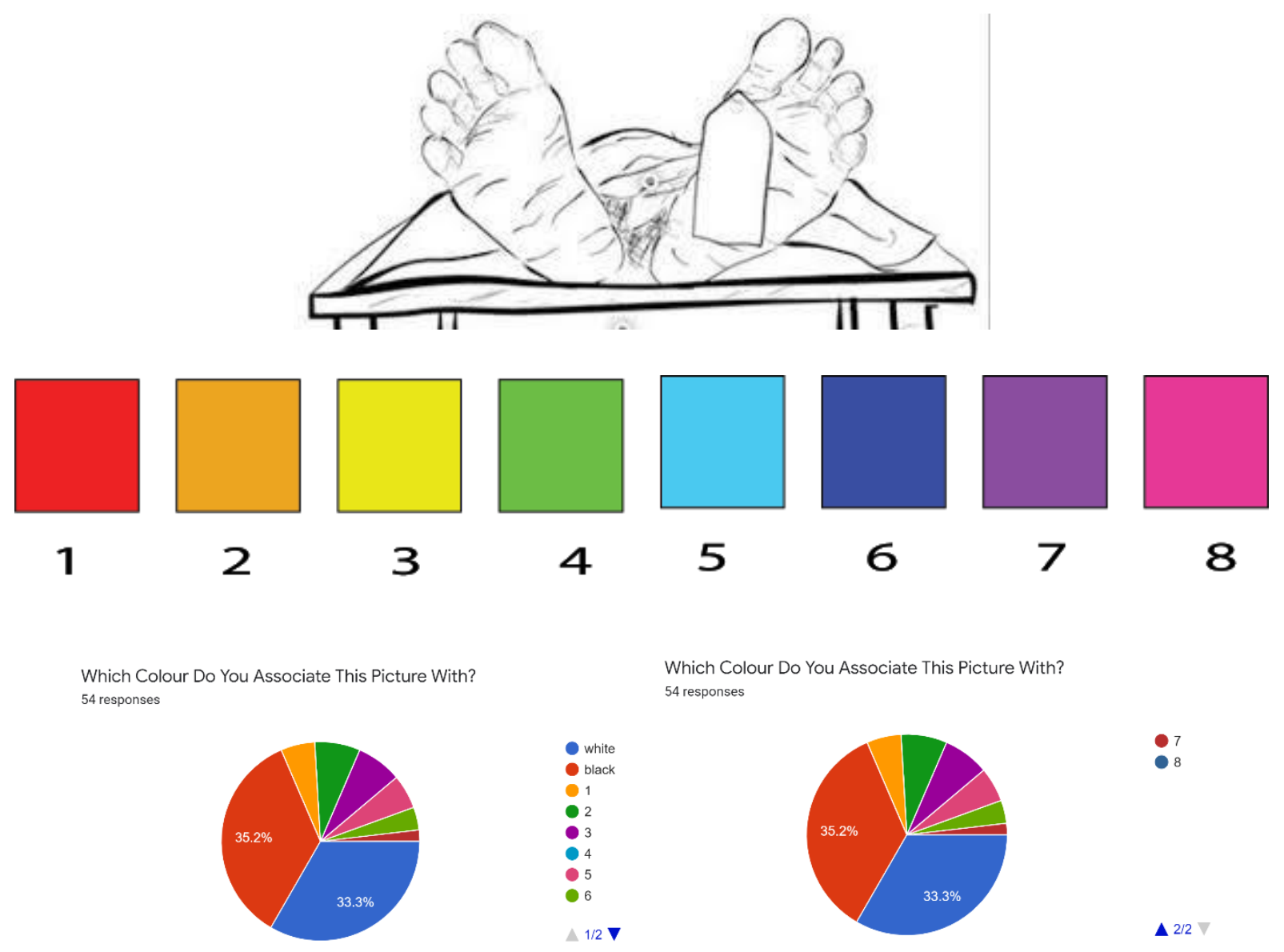

SECTION - 4: The third section tested respondents on the colours they symbolically associated to different words. Different phrases were employed to perceive what colour symbolized a word for our respondents.

balanced, calm, clean, pure, safe

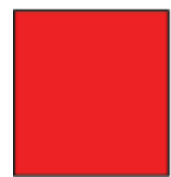

1

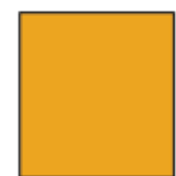

2

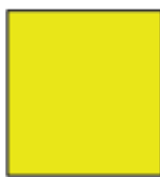

3

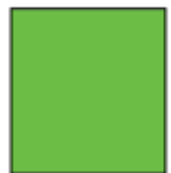

4

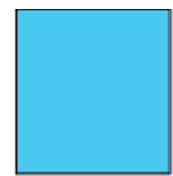

5

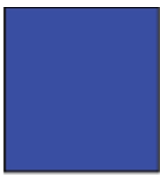

6

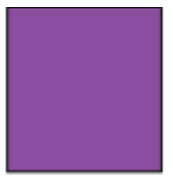

7

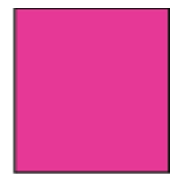

8 
International Journal of Social Science and Economic Research

ISSN: 2455-8834

Volume:06, Issue:05 "May 2021"

balanced, calm, clean, pure, safe

54 responses

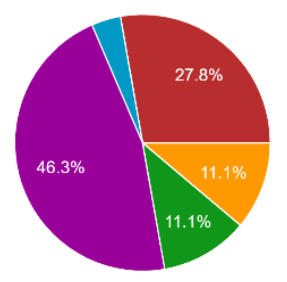

balanced, calm, clean, pure, safe

54 responses

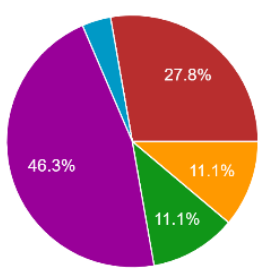

$\Delta 2 / 2$

confident, dependable, peaceful, stable, trustworthy

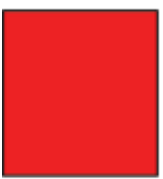

1

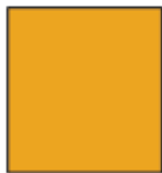

2

confident, dependable, peaceful, stable, trustworthy 54 responses

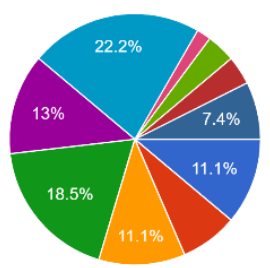

3
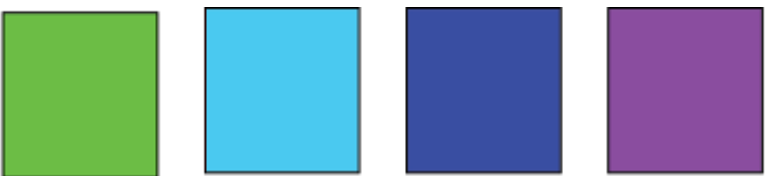

45

6

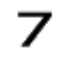

confident, dependable, peaceful, stable, trustworthy 54 responses
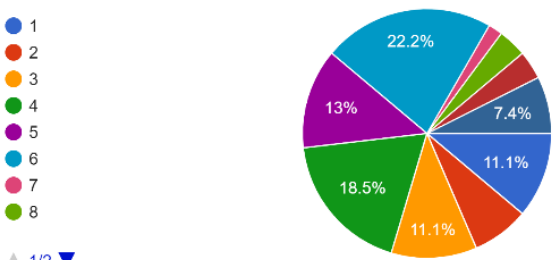

$\Delta 2 / 2 \nabla$

compassionate, energetic, exciting, playful, sweet

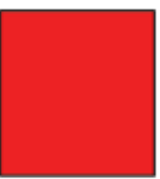

1

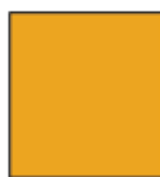

2

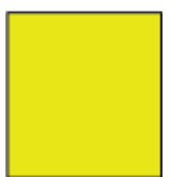

3

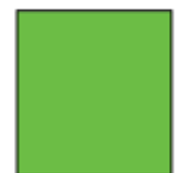

4

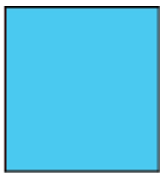

5

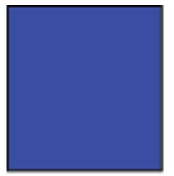

6

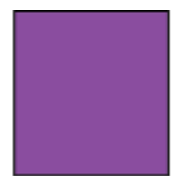

7
8

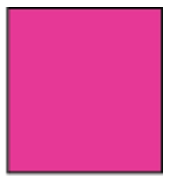


International Journal of Social Science and Economic Research

ISSN: $2455-8834$

Volume:06, Issue:05 "May 2021"

compassionate, energetic, exciting, playful, sweet 54 responses

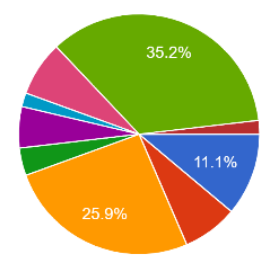

fresh, harmonious, healthy, hopeful, soothing
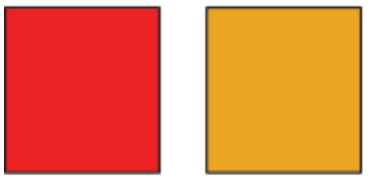

1

2

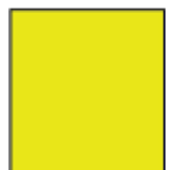

3

fresh, harmonious, healthy, hopeful, soothing 54 responses
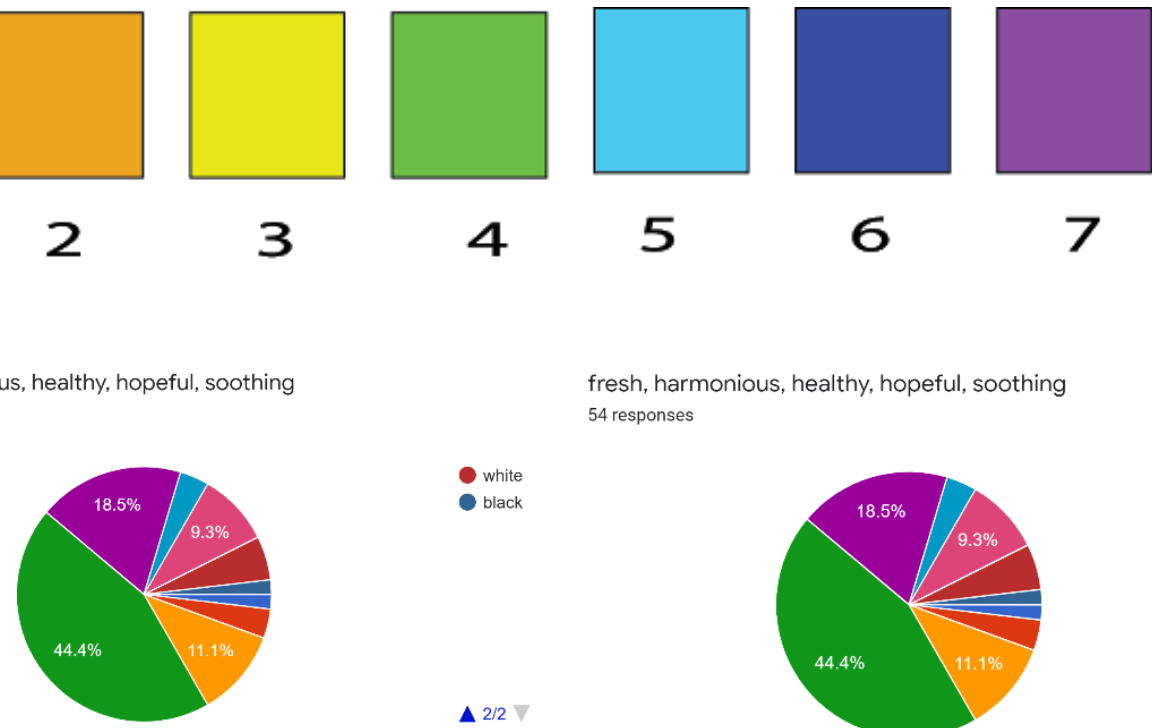

4

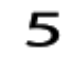

6

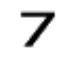

8

fresh, harmonious, healthy, hopeful, soothing 54 responses

white

black

$\Delta 2 / 2 \nabla$

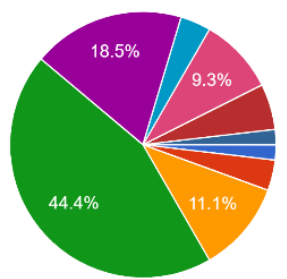

happy, honorable, intelligent, joyful, optimistic

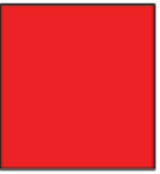

1

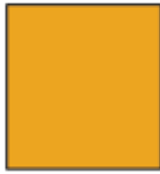

2

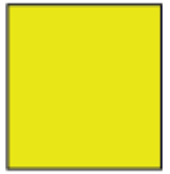

3

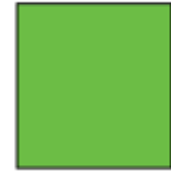

4

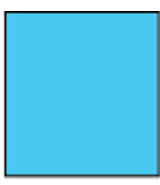

5

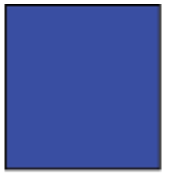

6

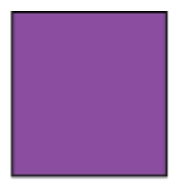

7

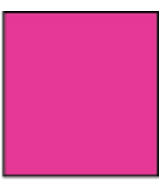

8 
International Journal of Social Science and Economic Research

ISSN: $2455-8834$

Volume:06, Issue:05 "May 2021"

happy, honorable, intelligent, joyful, optimistic 54 responses
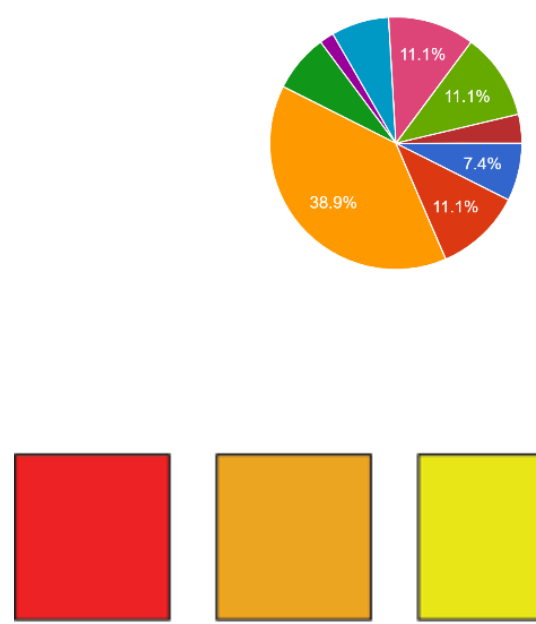

1

opulence, royalty 54 responses

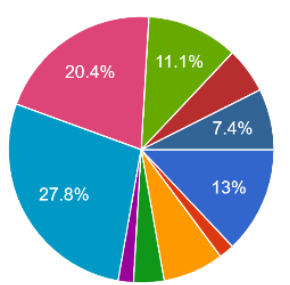

happy, honorable, intelligent, joyful, optimistic 54 responses

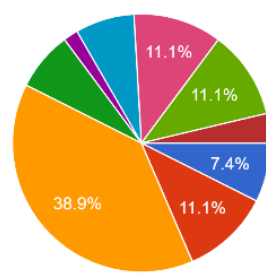

white

1

2

4

5

6
8

$\Delta 1 / 2 \boldsymbol{\nabla}$

opulence, royalty
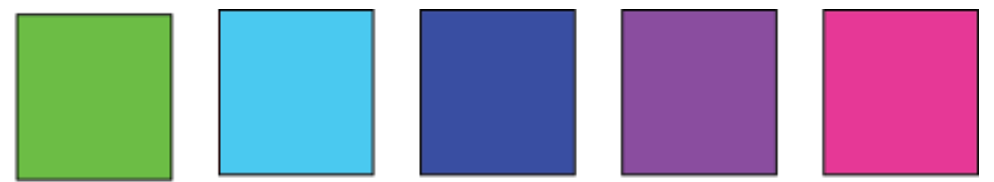

4

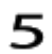

6

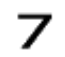

8

pulence, royalty 54 responses
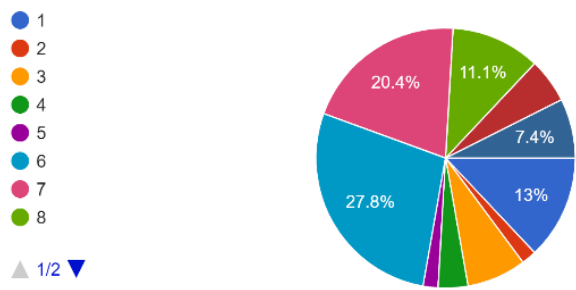

white

black

$\Delta 2 / 2 \nabla$

SECTION - 5: The fifth section asked respondents to select an alternative visual theme for print advertisements to test what colours they associated with the products being supplied by the company. 
International Journal of Social Science and Economic Research

ISSN: 2455-8834

Volume:06, Issue:05 "May 2021"
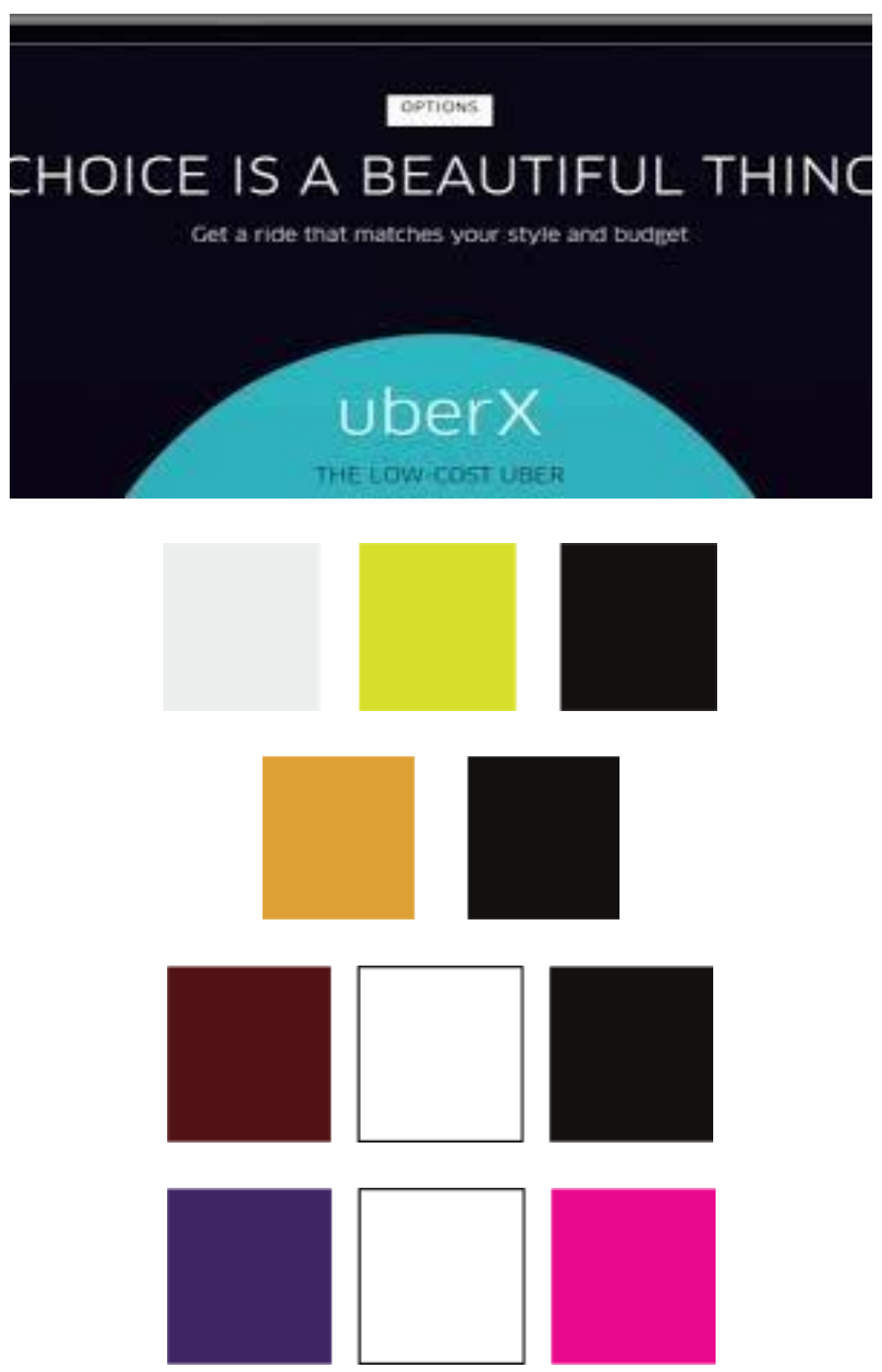
Alternate Visual Theme For A Taxi App :

54 responses

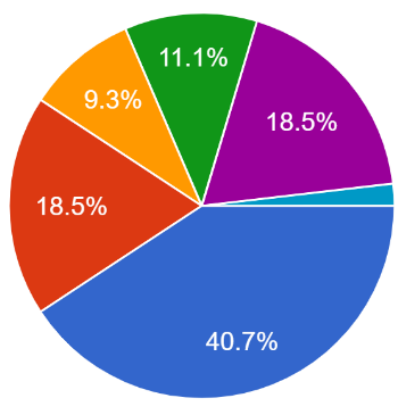

Option 1

Option 2

Option 3

Option 4

Just Like It Is

red and green white
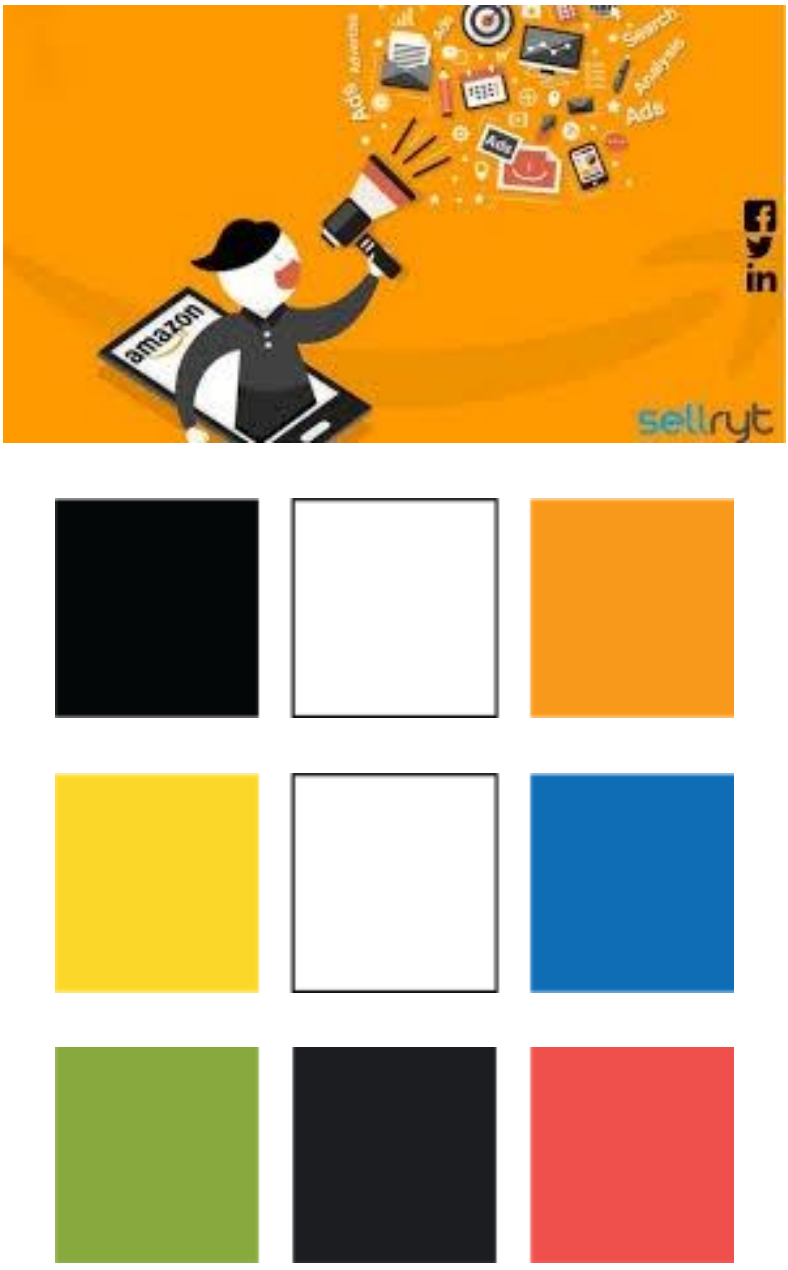

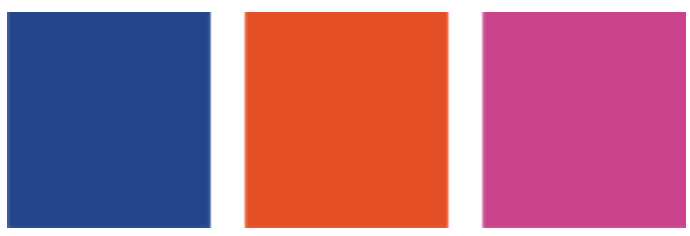

Alternate Visual Theme For An E-Commerce App :

54 responses
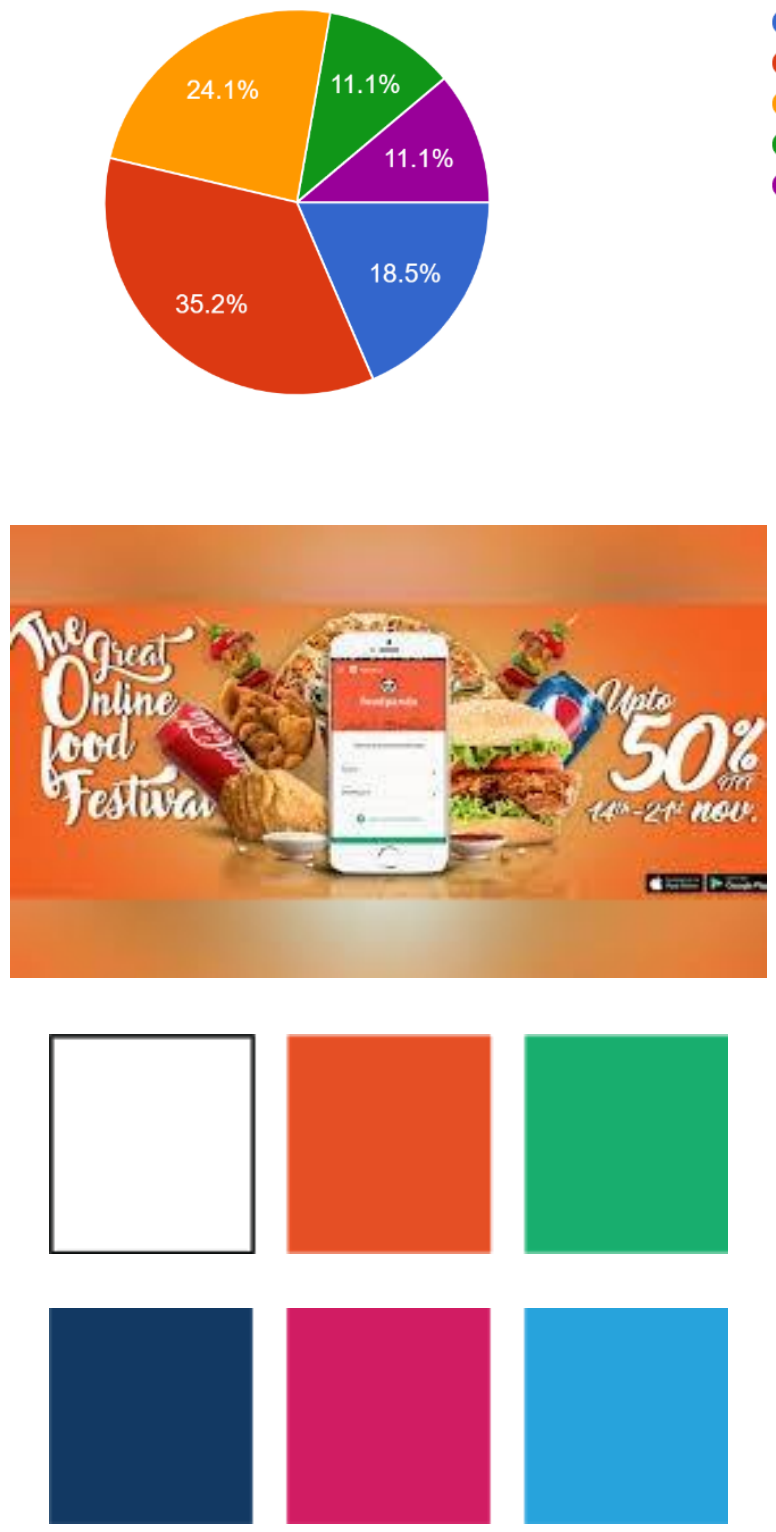

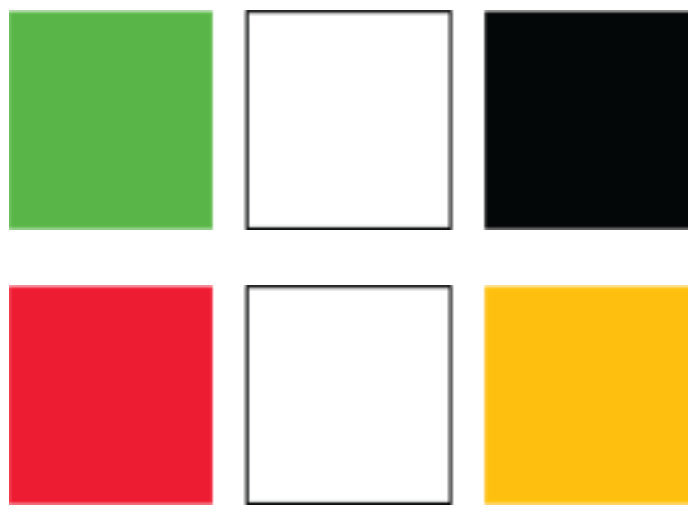

Alternate Visual Theme For A Food Delivery App :

54 responses

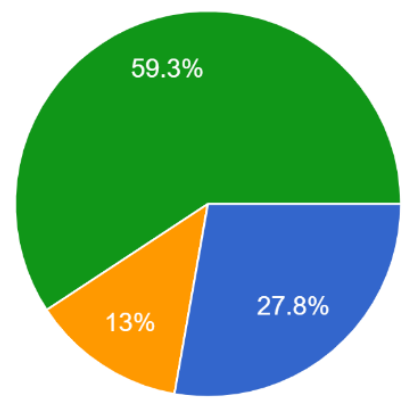

Further analyses were done to research the dichotomy in colour symbolism in both the countries situated in different continents.

\section{CONCLUSION}

Colour is the fundamental building block of visual symbols that serves as a means of communication. Colours can represent experiences, emotions, status, and other types of information that are difficult to convey in written or spoken language (Vikova, Vik \& Kania 2015). They evoke different emotions and beliefs in different people as they have different positive and negative connotations in different cultures. The power of colour comes from its symbolic meaning for the people.

The findings have shown that certain factors affect colour preferences. Data was found to both support and refute this hypothesis. The responses to some emotions have been uniform. The reasons for some emotions being denoted with the same colour in both countries are varied. Internet trends among social media may be responsible for suggesting what various colours 


\section{International Journal of Social Science and Economic Research}

ISSN: $2455-8834$

Volume:06, Issue:05 "May 2021"

should be attributed to. Responses to colour preference to emotions of anger, sadness, anger, wealth can therefore be attributed to globalization and the ease of sharing and accessing information online.

When we look at colour preferences to weddings and death a contrast in responses can be seen. This can be attributed to cultural factors. For example, Christianity is the most widely followed religion in Germany in which black is a colour of mourning and white is the traditional colour of bridal dresses. This is reflected in the responses. In India, Hinduism is one of the most widely followed religions in which white is worn after the death of a family member and red is the traditional colour for brides. This highlights the impact of cultural differences in affecting colour preferences.

Among older people, subdued colours were found to be of higher preference and the youth preferred more vibrant colours. Moreover, the older generation selected visual themes similar to what they saw in their childhood and preferred it for the colour themes of online companies. The colour blue was attributed to an emotion of youth and vibrancy.

However, the Blue seven phenomenon, that was reported by Simon (1971) and Simon and Primavera (1972) stands confirmed in our research with more than fifty per cent of the people from both the countries having blue as their most preferred colour. This is a universal phenomenon and therefore cultural, geographical or environmental factors did not influence in determining this preference.

An influence of geographical factors such as climate was also seen. People from Germany preferred cooler colours like green, blue, purple and its shades while on the other hand people from India preferred warm colours like yellow, red and orange. This can also be supported by psychologist E.R. Jaensch's research on how the climate in which we live influences our colour preferences.

The hypothesis that culture impacts the way we perceive colour symbolically in German and Indian context stands true. In our findings, substantial differences in colour preferences and association of colour with different emotions and objects are seen. There are however some emotions that are interpreted in the same way in both the countries which we attribute to globalisation and ease of sharing information on the internet.

The impact of colour translatability could not be effectively studied since the English language was used as a common medium to collect responses from Indian and German participants.

The research gap in the research paper is that due to the existence of geographical factors the sample size remained small and there was greater dependence on secondary data. With Germany 
International Journal of Social Science and Economic Research

ISSN: 2455-8834

Volume:06, Issue:05 "May 2021"

and India being very large countries with varied cultural differences within their states, there is a need for more extensive research.

\section{HYPOTHESIS}

Culture, linguistics as well as geographical factors influence how someone perceives colour. Upon analysis of the test results, it was inferred that the hypothesis could be accepted or rejected but could not be proven to be correct. Thus, it is an alternative hypothesis or experimental hypothesis. It was found out that between the independent and dependent variables, a relationship existed. The independent variable was the variable that was manipulated to find out whether it influenced the dependent variable. The independent variable were culture, language and geographical factors.Due to secondary data/literature review, we could infer the Onedirectional hypothesis - culture does play a role in how people of the same culture perceive colour.

\section{REFERENCES}

1. Understanding colour perception and preference by Anya Hurlbert and Yazhu Ling, Newcastle University, UK(2017)

2. Colour Symbolism And Its Cognitive-Cultural Message by Naira Gaparayan \& Karine Asatryan(2011)

3. The Non-Designer's Design Book by Robin Williams (1994)

4. Winick, C.: Taboo and disapproved colors and symbols in various foreign countries (1963)

5. Adams, F.M., Osgood, C.E.: A cross-cultural study of the affective meaning of color(1973)

6. The Diversity of Color: an Analysis of Cross-cultural Color Symbolism by Erica L. Bradfield (2014)

7. Saito, M.: Ajianiokeru Shikisai Shikouno Kokusaihikakukenkyu Nikkanhikaku Shiroshikouni Chakumokushite (A cross-cultural survey on color preference in Asian countries - comparison between Japanese and Koreans with emphasis on preference for white (1992)

8. Shen, N.C.: The color preference of 1368 Chinese students, with special reference to the most preferred color (1937)

9. Simon, W.E.: Number and color responses of some college students: preliminary evidence for a "Blue Seven Phenomenon".(1971) 
International Journal of Social Science and Economic Research

ISSN: 2455-8834

Volume:06, Issue:05 "May 2021"

10. Boutwell and Fennel: blue-Seven Phenomenon (1974)

11. Most and Least Preferred Colours Differ According to Object Context: New Insights from an Unrestricted Colour Range byDomicele Jonauskaite, Christine Mohr, Jean-Philippe Antonietti,Peter M. Spiers, Betty Althaus, Selin Anil, Nele Dael (2016)

12. Adams, F.M., Osgood, C.E.: A cross-cultural study of the affective meaning of color. (1973)

13. Translating Colours-A Cognitive-Linguistic Research Project on Translating Colour Words and Colour Metaphors into Estonian : Mari Uusküla\&

14. Culture Differences of Basic Color Terms In Translation: Emily Claire (2017)

15. Colour Preferences and Cultural Variation:A. Choungourian(1968)

16. Scott-Kemmis, J. (n.d.). Cultural Color: Cultural Meanings of Color \& Color Symbolism.

17. De Bortoli M., Maroto J. Colours Across Cultures: Translating Colours in Interactive Marketing Communication, 2001.

18. Eysenck, H.J.: A critical and experimental study of color-preferences. Am. J. Psychol. 54, 385-394 (1941)

19. Adams, F.M., Osgood, C.E.: A cross-cultural study of the affective meaning of color. J. Cross-Cult. Psychol. 7, 135-157 (1973)

20. Allan, K. (2009), “The Connotations of Color Terms: Color Based X-phemisms,” Journal of Pragmatics, 41(3), 626-637.

21. Byrne, Marie. 'Culture \& Communications: Similarities of Color Meanings among Diverse Cultures' the Journal of Global Issues \& Solutions. BWW Society, 2003

\section{APPENDIX}

1. The google form circulated to collect responses is attached herewith. (https://forms.gle/HqBLWHjehBYkDdxt7).

2. The responses to the online survey circulated among Indian and German respondents is attached.(https://docs.google.com/spreadsheets/d/1FzQzm461ME7kNE2w4OHd9p3NqILH n9czdUxC98ncZ4/edit?usp=sharing)

3. Berlin and Kays's eleven basic color elements (Berlin, B. \& Kay, P. (1969). Basic color terms: Their universality and evolution. Berkeley \& Los Angeles: University of California Press) 